\section{Pacific Northwest}

National Laboratory

Operated by Battelle for the

U.S. Department of Energy

\title{
Independent Review of Tank 241-AY-101 Fitness for Service
}

\author{
C.W. Stewart (Editor) \\ $\underline{\text { Review Team }}$ \\ S.H. Bush * G.J. Posakony \\ C.H. Delegard F.A. Simonen \\ M.R. Elmore M.T. Terry \\ A.B. Johnson \\ P.E. Zapp ${ }^{* *}$ \\ A.F. Pardini \\ * Review \& Synthesis Associates \\ ** Westinghouse Savannah River
}

February 2003

Prepared for the U.S. Department of Energy under Contract DE-AC06-76RL01830 


\title{
DISCLAIMER
}

This report was prepared as an account of work sponsored by an agency of the United States Government. Neither the United States Government nor any agency thereof, nor Battelle Memorial Institute, nor any of their employees, makes any warranty, express or implied, or assumes any legal liability or responsibility for the accuracy, completeness, or usefulness of any information, apparatus, product, or process disclosed, or represents that its use would not infringe privately owned rights. Reference herein to any specific commercial product, process, or service by trade name, trademark, manufacturer, or otherwise does not necessarily constitute or imply its endorsement, recommendation, or favoring by the United States Government or any agency thereof, or Battelle Memorial Institute. The views and opinions of authors expressed herein do not necessarily state or reflect those of the United States Government or any agency thereof.

\author{
PACIFIC NORTHWEST NATIONAL LABORATORY \\ operated by \\ BATTELLE \\ for the \\ UNITED STATES DEPARTMENT OF ENERGY \\ under Contract DE-ACO6-76RLO183O
}

Printed in the United States of America

Available to DOE and DOE contractors from the

Office of Scientific and Technical Information,

P.O. Box 62, Oak Ridge, TN 37831-0062;

ph: (865) 576-8401

fax: (865) 576-5728

email: reports@adonis.osti.gov

\begin{abstract}
Available to the public from the National Technical Information Service,
U.S. Department of Commerce, 5285 Port Royal Rd., Springfield, VA 22161

ph: (800) 553-6847

fax: (703) 605-6900

email: orders@ntis.fedworld.gov

online ordering: http://www.ntis.gov/ordering.htm
\end{abstract}

This document was printed on recycled paper.

$(8 / 00)$ 



\title{
Independent Review of Tank 241-AY-101 Fitness for Service
}

\author{
CW Stewart (Editor) \\ $\underline{\text { Review Team }}$ \\ SH Bush ${ }^{\text {(a) }}$ \\ GJ Posakony \\ $\mathrm{CH}$ Delegard \\ FA Simonen \\ MR Elmore \\ MT Terry ${ }^{(b)}$ \\ AB Johnson \\ PE Zapp ${ }^{(c)}$ \\ AF Pardini
}

February 2003

Prepared for

the U.S. Department of Energy

under Contract DE-AC06-76RLO 1830

Pacific Northwest National Laboratory

Richland, Washington 99352
(a) Review \& Synthesis Associates
(b) Los Alamos National Laboratory
(c) Savannah River Technology Center 



\begin{abstract}
Video inspections in the annulus of Hanford double-shell waste storage tank 241-AY-101 in 2001 and earlier showed rust over large areas of the primary tank and secondary liner walls. These observations led to extensive nondestructive inspections and analyses to determine the extent and severity of the corrosion and to correct several operational deficiencies that contributed to the problem. PNNL has performed an independent review of the accumulated evidence from these efforts to determine whether unacceptable conditions were corrected and whether the current condition of the tank meets or exceeds technical and operational requirements. The findings of this review are the subject of this report. The conclusion is that AY-101 is fit for service without restriction subject to several recommendations for further inspections and analyses.
\end{abstract}




\section{Executive Summary}

The two double-shell tanks in the AY tank farm in the Hanford 200 East Area were constructed between 1968 and 1970 to store highly radioactive aging waste from the PUREX plant. Tank 241-AY-101 (AY-101) initially entered service in April 1971 and was used actively until 1988. The tank remained relatively full until 1997, when much of the waste was pumped out. The waste level was 65 inches in December 2002.

Corrosion was first observed in AY-101 in 1992, when limited video inspections in the annulus showed rust on areas of the primary tank and secondary liner walls. In late 1999, ultrasonic testing (UT) inspections of the annulus side of the primary tank failed because heavy corrosion product prevented the wheels of the magnetic crawler test vehicle from clinging to the wall. Further video inspection in January and February 2001 showed extensive corrosion on the walls of the annulus and the interior of primary tank, particularly in the historic "waterline" band between about 320-360 inches, where the waste level had remained for long periods. The video also showed a stain pattern that suggested a leakage of water through the primary tank wall from the annulus. This was the principal concern that caused CH2M HILL Hanford Group, Inc. (CH2M HILL) to issue an occurrence report, as required by the U.S. Department of Energy (DOE), and to limit the maximum waste level to 80 inches, far below the apparent leak site.

The annulus ventilation system had been inoperable with the inlet dampers closed for about 10 years, leading to the hypothesis that the corrosion was the result of water intrusion into the annulus area without ventilation to remove it. The waste chemistry had also been out of specification for at least seven years, a factor that was expected to have aggravated primary side corrosion, especially in the waterline band.

The ventilation system was restored to operation in April 2001, and a leaky valve in the service water system, a probable source of water intrusion, was found and corrected. The waste chemistry was brought back into specification in January 2001. Areas of the primary liner with the most severe corrosion, including the suspect stain area, were pressure cleaned and leak tested with negative findings. No radioactive contamination was found in material taken from the annulus, and neither the annulus leak detectors nor the continuous air radiation monitors had alarmed. The suspect stain area was also later identified as an area on the tank wall that was probably sprayed by liquid waste during waste transfer into the tank. Extensive nondestructive inspection using UT backed by extreme-value statistical analyses showed that the minimum measured wall thickness exceeds the minimum thickness determined from a very conservative structural analysis. Based on these findings, it was concluded that AY-101 is fit for service with no operational restrictions.

Pacific Northwest National Laboratory (PNNL) performed an independent review of the accumulated testing and analysis results to determine whether unacceptable conditions have been corrected and the current condition of the tank meets or exceeds technical and operational requirements. The review panel consisted of six PNNL and three outside experts in corrosion, nondestructive testing, structural mechanics, and chemistry. The primary conclusion from the review is that AY-101 is fit for service without restrictions, subject to several recommendations for further inspections and analyses. The major recommendations are as follows: 
1. Perform a UT inspection of the primary liner two years after the historic liquid/air interface band is re-wetted. The inspection should cover the same $32-\mathrm{ft}$ by 30 -inch region of the primary liner between 321 and 351 inches that was inspected through riser 89 in fiscal year 2002. Using the 2002 UT data as a baseline, a comparison can be made to evaluate corrosion rates and show that the tank wall thickness remains within acceptable limits. It is also recommended that this UT inspection extend to the primary liner at the new waste level if it is above the historic waterline.

2. Extend the planned UT inspection of the secondary liner to include the annulus floor. UT inspection should be performed on selected areas of the annulus floor in sectors where significant corrosion was observed on the walls, checking for both pitting and cracks. Though it may be difficult, the inspections should include several areas that have been buried under debris or corrosion product, including a weld region if possible. The inspection need not be done prior to removing the waste level restriction.

3. Perform psychrometric analysis on the annulus exhaust to confirm correction of water intrusion. The leaky service water valve that was found and isolated may not be the only source of water intrusion. As part of the fitness-for-service evaluation, the absence of water inflow must be confirmed by repeating the psychrometric analysis that detected the original leak. Consideration should be given to an additional psychrometric evaluation after a large rainfall.

4. Verify that annulus leak detectors (including secondary leak detection wells) and continuous air monitors are operational. Though the inspections did not find any leaks in the primary liner nor areas of inadequate wall thickness, the corrosion was significant, and much less than $100 \%$ of the primary liner surface was inspected. It is therefore prudent to ensure that leak detection systems are operational before the tank is refilled above the current 80 -in. restriction.

$\mathrm{CH} 2 \mathrm{M}$ HILL has reviewed and accepted these recommendations and is engaged in accomplishing them. 


\section{Contents}

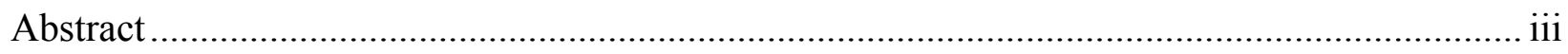

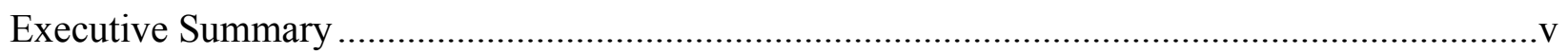

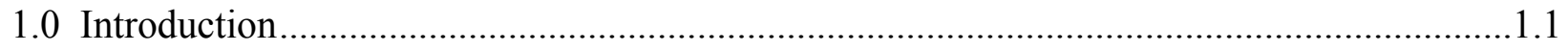

2.0 Summary of Evidence for AY-101 Fitness for Service ........................................................

2.1 Conditions Leading to Current Operating Restrictions ......................................................2.1

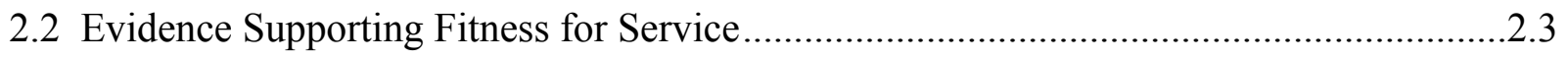

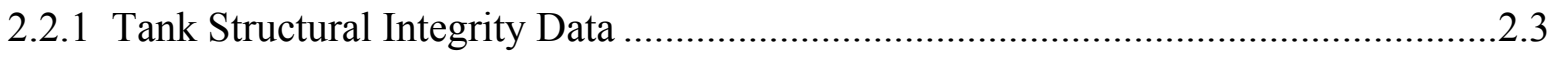

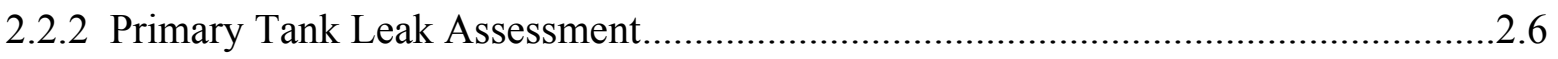

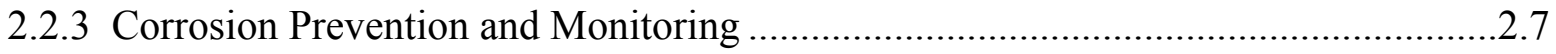

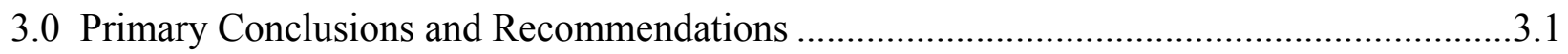

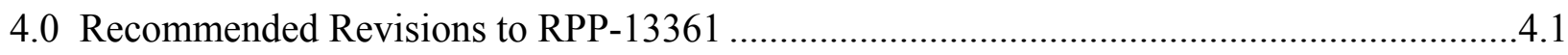

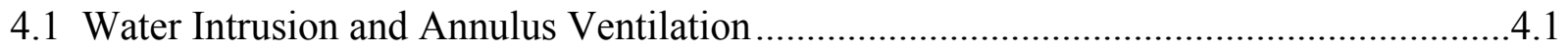

4.1.1 Confirm That No Future Leak Is Possible from fhe Defective Valve ......................... 4.1

4.1.2 Describe Potential for Water to Leak Between the Secondary Liner
and Concrete Shell............................................................................................

4.1.3 State Current Annulus Ventilation Rate and Evaporative Capability .......................... 4.2

4.1.4 Describe Why the Annulus Ventilation System Cannot Operate if the Waste Level Is Too Low ………………...............................................................

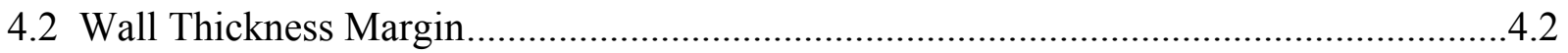

4.2.1 Describe Structural Analyses That Are the Basis for Minimum Wall Thickness ......4.2

4.2.2 State That High-Risk Areas Similar to Those That Couldn't Be Cleaned

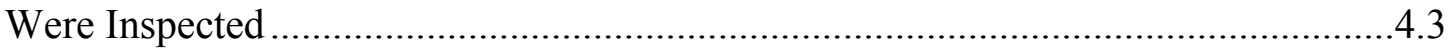

4.2.3 Clarify That the Waterline Is a Band, Not a Level ...................................................

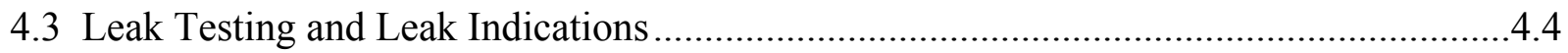

4.3.1 Determine Personnel Qualifications and Standards Used in Tracer Gas Testing ........4.4

4.3.2 Expand Discussion Attributing Interior Stains to Waste Transfer Operation...............4.5

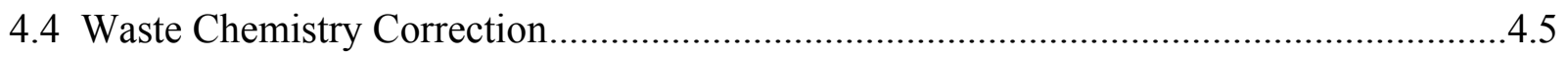

4.5 Tank Bottom Inspection......................................................................................

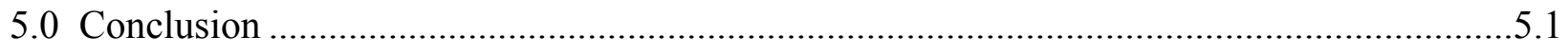

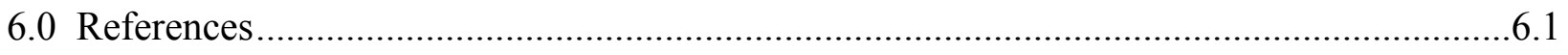

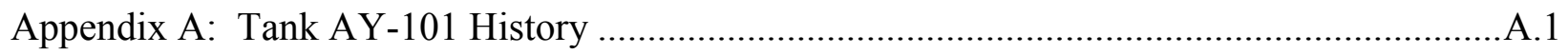

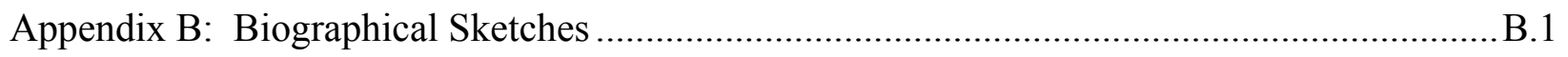

Appendix C: Acceptance of Recommendations by CH2M HILL ................................................ 


\section{Figures}

1.1 Typical Double-Shell Tank Cross Section......................................................... 1.1

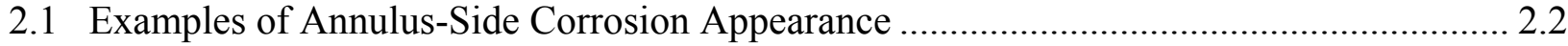

2.2 Examples of Primary-Side Corrosion Appearance ….................................................... 2.3

2.3 Minimum and Measured Wall Thickness in AY-101 ................................................... 2.6

A.1 Tank AY-101 Plan View and Riser Map .................................................................. A.2

A.2 Tank AY-101 Section View................................................................................. A.5

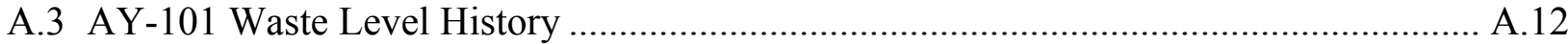

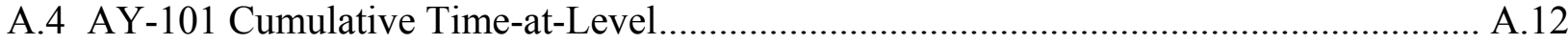

A.5 AY-101 Recent Waste Temperature History .............................................................. A.13

\section{Tables}

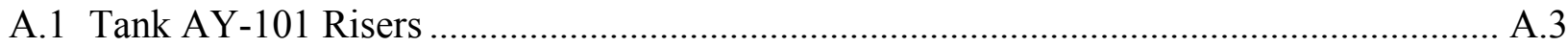

A.2 Nitrite/Nitrate Concentration Ratio.......................................................................... A.8

A.3 Mean Segment Level Concentration of Selected Metals in Sludge................................ A.9

A.4 AY-101 Best Basis Inventory Source Data .............................................................. A.11 


\subsection{Introduction}

The AY and AZ tank farms were constructed between 1968 and 1970 in the Hanford 200 East Area to store highly radioactive aging waste from the PUREX plant. The AY tank farm contains two double-shell tanks (DSTs), each with a capacity of $1,000 \mathrm{kgal}$, a diameter of $75 \mathrm{ft}$, and an operating waste depth of $30.33 \mathrm{ft}$. These tanks were designed specifically to store boiling, high-heat-generating waste at a maximum temperature of $350^{\circ} \mathrm{F}$ for sludge and $260^{\circ} \mathrm{F}$ for liquid. AY-101 initially entered service in April 1971 and was used actively until 1988. The waste level remained in the 320-360-inch range until 1997, when the tank was pumped down to about 52 inches. In December 2002 the waste level was 65 inches. A detailed description of the tank, its history, and its contents is given in Appendix A.

DSTs consist of an inner primary carbon steel tank surrounded by a secondary carbon steel liner inside a reinforced concrete shell. The primary tank and secondary liner are separated radially by an annular space about $3.5 \mathrm{ft}$ wide. An 8 -inch-thick insulating concrete pad separates the bottoms of the primary and secondary liners. A grid of radial slots is formed in the insulating concrete pad between the primary and secondary liners to allow air circulation for cooling and to drain any leakage from the primary tank to leak detectors in the annulus. The primary tank bottom is flat except for a rounded segment called the lower knuckle that joins the bottom to the walls. This configuration is shown in cross section in Figure 1.1. Additional design features and details are given in Berman (2002).

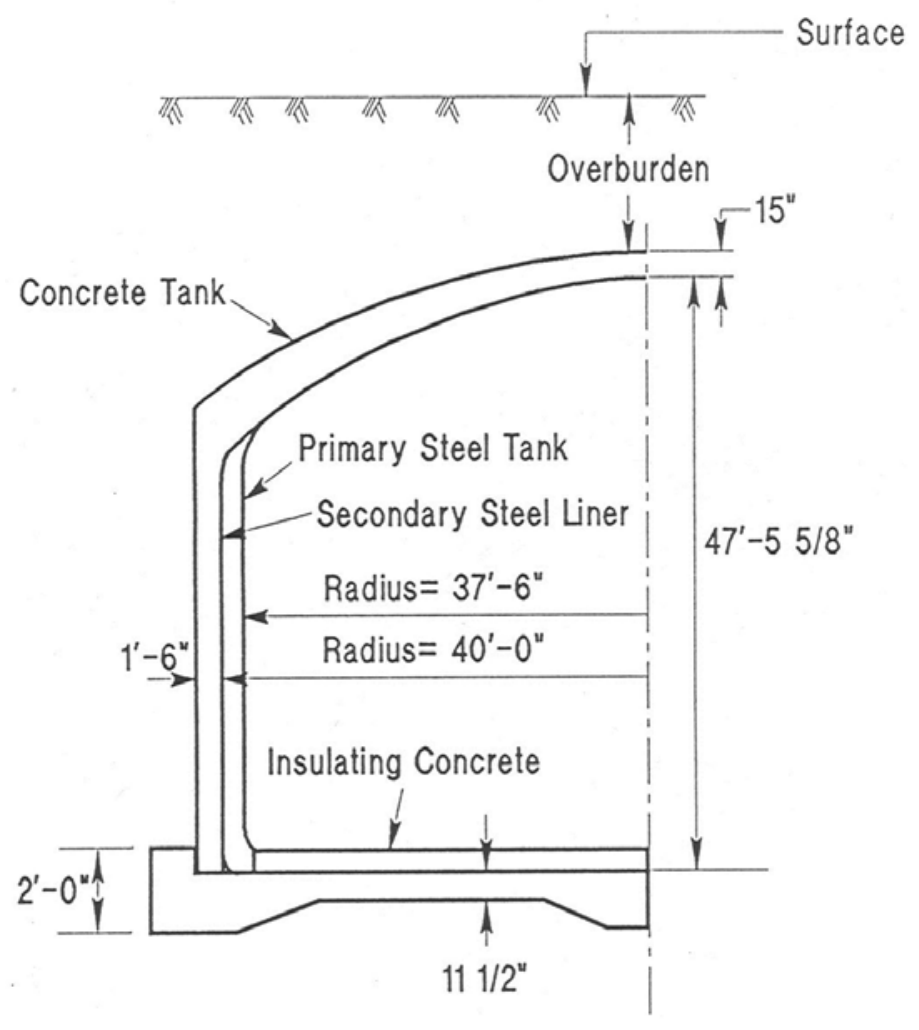

Figure 1.1. Typical Double-Shell Tank Cross Section 
Ventilation of the primary tank is required to prevent flammable gas accumulation and to prevent unfiltered releases by keeping the headspace pressure negative. It is also the primary means of waste cooling. The primary ventilation systems in each DST farm are driven by a single induced draft fan that serves the entire farm. The total flow is distributed among the tanks in the farm by adjusting dampers in the tank inlet ducts. Ambient air is drawn into the tank headspace through inlet filters. The headspace exhaust then flows through high-efficiency particulate air (HEPA) filters into a manifold and discharges to the atmosphere through the tank farm stack. The induced draft creates a vacuum of 2 to 5 inches of water in the headspace. A major ventilation system upgrade was made on the AZ and AY tank farms in 1998. This upgrade included a new stack, ventilation fans, emission control equipment, emission monitoring equipment, and connecting piping, increasing the airflow rate from 800 to $1,050 \mathrm{cfm}$.

Annulus ventilation keeps the annulus dry and also cools the waste. Each tank farm normally has its own annulus ventilation system. An exhaust fan draws outside air through an inlet damper, a pre-filter, and a high-efficiency filter and distributes it to the annulus through several ducts and to the radial slots in the tank bottom through an air distribution chamber in the center of the concrete pad beneath the primary tank. AY-101 and AY-102 each have their own annulus exhaust train. The AZ tanks share a single train. The annulus ventilation flow rate was measured December 12, 2002 at 1,000 cfm in AY-101 and 1,075 cfm in AY-102 (increased as a special provision for storing the high-heat waste from C-106). Passive ventilation flow rates in the annulus are estimated to be on the order of $10 \mathrm{cfm}$ if the active ventilation system is shut down.

In the AY and AZ tanks, a drain for the annulus pump pit opens to the primary tank at the 64-inch elevation. When the waste level is below 64 inches, the drain forms a flow path between the primary tank headspace atmosphere and the annulus. In this condition, the annulus ventilation is required to be shut down to prevent unfiltered release of the primary tank atmosphere to the environment.

Detection of leaks from the primary tank is provided by electrical contact probes mounted about $1 / 2$ inch above the annulus floor. These detectors alarm if a leak causes liquid to reach the contact probes. Continuous air monitors (CAMs) are installed to detect radioactivity in the annulus atmosphere. These systems draw air through a filter to collect particulates. When the integrated radioactivity on the filter exceeds a threshold value the CAM alarms.

Video inspections in the annulus in 1992 and early 2001 showed rust on large areas of the primary tank and secondary liner surfaces and the interior of the primary tank, particularly in the historic "waterline" band where the waste level had remained for long periods. The corrosion product buildup was so severe that the wheels of the magnetic crawler used for ultrasonic testing (UT) lost contact with the primary wall when inspections were attempted in late 1999. Stains on the primary tank interior suggested leakage of water from the annulus side. This potential tank perforation prompted $\mathrm{CH} 2 \mathrm{M}$ HILL to submit an occurrence report and to limit the waste level to a maximum of 80 inches.

The annulus ventilation system had been shut down with the inlet dampers closed for about 10 years, leading to the theory that the corrosion was the result of water intrusion into the 
annulus area that was not removed by ventilation. The intrusion was postulated to result from a leak in the service water system or precipitation runoff. The waste chemistry had also been out of specification for at least seven years, which was expected to have aggravated primary side corrosion, especially in the waterline band.

The ventilation system was restored to operation in April 2001, and a leaking service water valve, a probable source of water intrusion, was found and isolated. Caustic was added to the tank in January 2001, and subsequent grab and subsequent core samples confirmed that the waste chemistry had been brought back within specification. Areas of the primary liner with the most severe corrosion, including the suspect stain area, were leak tested with negative findings. The suspect stain area on the inner wall of the primary liner was later attributed to waste being sprayed on the tank wall during waste transfer into the tank. Extensive UT inspection and extreme-value statistical analyses showed that the measured wall thickness exceeds the minimum requirements derived from a conservative structural analysis. These findings were compiled in Tank 241-AY-101 Fitness for Service (Berman 2002), which concluded that Tank AY-101 is fit for service with no operational restrictions.

CH2M HILL asked PNNL to perform an independent review of Berman's report to determine whether unacceptable conditions have been corrected and whether the current condition of the tank meets or exceeds technical and operational requirements. A panel of six PNNL and three outside experts in corrosion, nondestructive testing, structural mechanics, and chemistry was chosen to perform the review. Biographical sketches of panel members are given in Appendix B. Five of the nine reviewers served on the senior review committee organized for CH2M HILL by PNNL in May 2001 to assess the Hanford Double-Shell Tank Integrity project (Stewart et al. 2001).

The team reviewed Berman's report and other supporting documents and data from November 19 to December 2, 2002. On December 3 the team met to discuss their findings and to reach consensus on comments. The conclusions and recommendations from this meeting were reported to CH2M HILL on December 10. The primary conclusion from the review is that Tank AY-101 is fit for service without restrictions subject to several recommendations for further inspections and analyses. CH2M HILL has reviewed and concurred with these recommendations. A copy of the letter from CH2M HILL expressing agreement with the review and committing to accomplish the recommended actions is attached as Appendix $\mathrm{C}$.

This report presents the conclusions and recommendations of this review and the rationale behind them. Section 2 provides a statement of the problem and a summary of the evidence showing that AY-101 is fit for service. The overall conclusions and recommendations of the review are given in Section 3, and suggested revisions to Berman (2002) are described in Section 4. The overall conclusions are stated in Section 5, and references are listed in Section 6. 



\subsection{Summary of Evidence for AY-101 Fitness for Service}

This section gives a concise description of the challenge to Tank AY-101's integrity (Section 2.1) and a summary of the tests, inspections, and analyses supporting its fitness for service (Section 2.2). It is not intended to duplicate the detailed description available in Berman (2002) but to briefly provide the necessary background and context for the review team's concerns and conclusions. This information is derived mainly from Berman's report but has been supplemented or modified by information developed during and after the review team meeting.

\subsection{Conditions Leading to Current Operating Restrictions}

The first indication that the tank had significant corrosion was in 1992 when video inspections in the annulus showed rust over many areas of the primary tank and secondary liner surfaces. In 1999 UT inspections were attempted on the annulus side of the primary tank. However the corrosion product on the wall was found to be so heavy that the magnetic crawler used for UT inspections could not cling to the wall and the effort had to be terminated.

This prompted further video inspections in January and February 2001 that revealed extensive and visually severe annulus-side corrosion on both the primary and secondary walls. Examples of this corrosion are shown in Figure 2.1. Corrosion was also observed on the interior of the primary tank, particularly in the historic "waterline" region between the 320- and 360-inch elevations where the waste level had remained for most of the tank's 30-year history (Appendix A, Section A.4 identifies the waterline bands). Figure 2.2 shows primary side corrosion.

Figure 2.2 also shows a stain pattern that was initially believed to indicate a leak in the primary tank wall. If the primary tank was indeed perforated, a water film causing corrosion on the annulus side could have been pulled through the wall by the ventilation-induced vacuum in the primary tank, especially with the annulus ventilation system shut down. This was the principal concern that led CH2M HILL to issue an occurrence report to DOE and to restrict the maximum waste level to 80 inches to keep the waste far below the apparent leak site until further studies could confirm the tank's fitness for service.

Observations and analyses indicated that corrosion on the annulus walls was the result of a water intrusion occurring when annulus ventilation was not available to remove it. The annulus ventilation system was shut down with the inlet dampers closed for about 10 years, from 1992 to 2001. When operating, this system is capable of evaporating water at a relatively high rate and should have kept the annulus dry, even with a sizeable intrusion (Anantatmula et al. 2001; Berman 2002). After the annulus ventilation system was restored in April 2001, a psychrometric analysis showed that more water was exiting in the annulus exhaust than was pulled in with the outside air. This led to the conclusion that there was a water intrusion into the annulus area from a service water system leak or precipitation runoff. Besides wetting the walls directly, the intruding water may have promoted a reflux cycle where water evaporated in the warmer area near the tank bottom, condensed near the top, and flowed down the walls. The corrosion product composition was consistent with free corrosion of steel exposed to moisture (Aftanas 2001). 


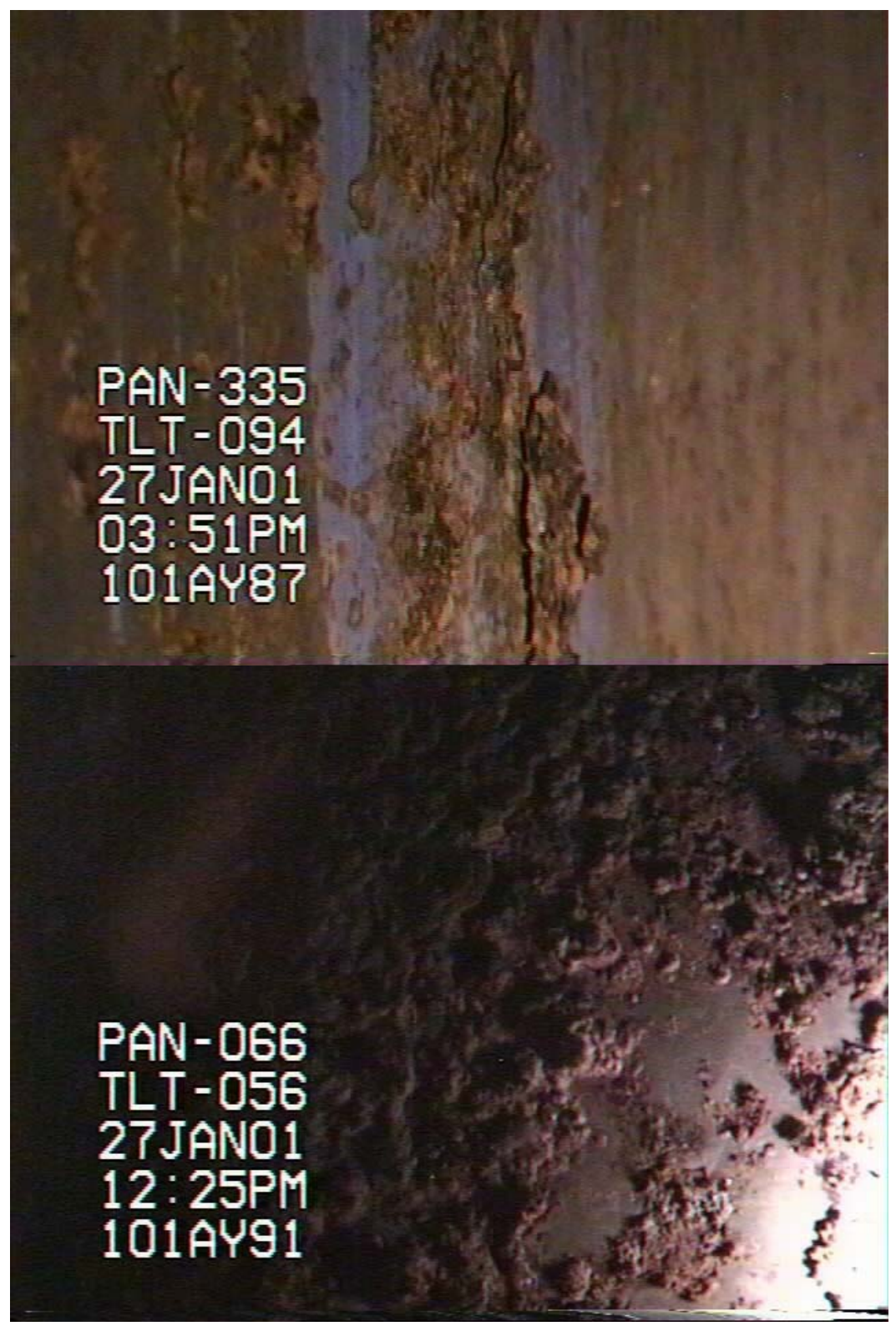

Figure 2.1. Examples of Annulus-Side Corrosion Appearance

The waste chemistry had also been out of specification for at least seven years. Analysis of grab samples taken in 1997 showed the $\mathrm{pH}$ as low as 9.4 in the supernate, and the hydroxide ion concentration was below 0.0074 M [Tank Waste Information Network System (TWINS) data, http://wins.pnl.gov:8001/twins3/twins.htm]. A hydroxide concentration of at least $0.01 \mathrm{M}$, corresponding to a $\mathrm{pH}$ of 12.0 , is required to satisfy the DST chemistry limits (Fort et al. 2001). This was expected to have aggravated primary side corrosion, especially in the waterline band, where the liquid wetting the exposed surfaces is more dilute and the presence of air tends to lower the $\mathrm{pH}$ due to the carbonate/bicarbonate buffer effect (Stewart et al. 2001). 


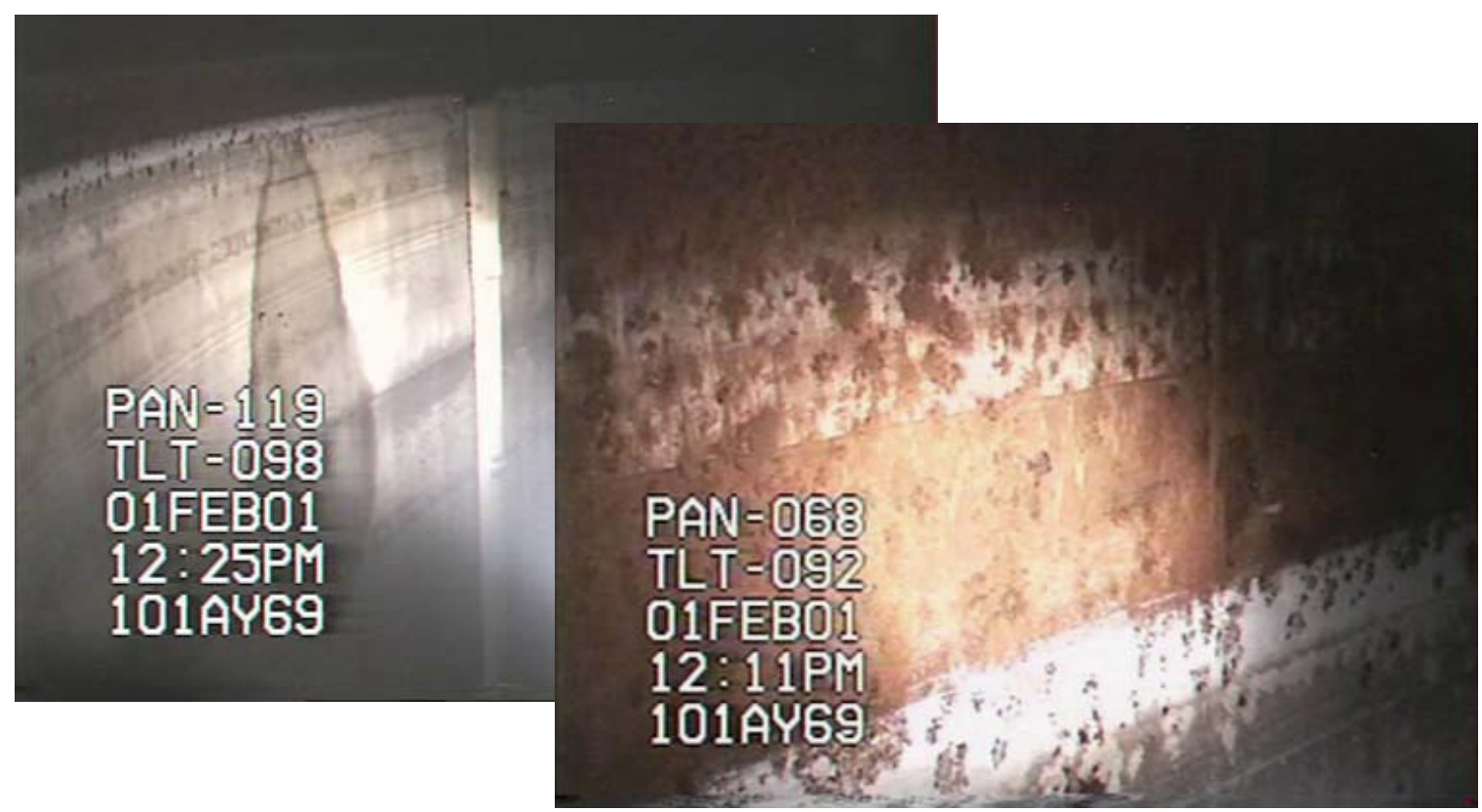

Figure 2.2. Examples of Primary-Side Corrosion Appearance

\subsection{Evidence Supporting Fitness for Service}

The evidence summarized in this section was developed while measuring the depth and extent of apparently severe corrosion and in discovering and correcting its causes. The detailed measurements and calculation results are presented in Berman (2002) and supporting documents. The evidence is divided into three categories. Section 2.2.1 describes the assessment of corrosion depth in terms of overall tank structural integrity, and Section 2.2.2 covers testing for leaks in the primary tank. Section 2.2.3 summarizes actions to correct the causes of the observed corrosion and to prevent or control future corrosion.

\subsubsection{Tank Structural Integrity Data}

Because a concrete shell does not support it, the primary tank wall requires a minimum thickness that varies with height to support the static and dynamic structural loads induced by the waste, dome loading, thermal expansion, and earthquakes. Structural integrity is assessed by measuring the actual wall thickness and comparing it with the allowable minimum thickness calculated by a detailed structural analysis.

The actual wall thickness was measured by UT. Because it is not practical to inspect $100 \%$ of the primary tank wall, extreme-value statistical analysis was applied to estimate the minimum thickness measurement based on the data from the area actually measured. The depth of individual pits was also measured using LazrLyne ${ }^{\mathrm{TM}}$ technology. ${ }^{\text {(a) }}$

(a) LazrLyne is a trademark of C-Map Systems, Inc., Red Lodge, Montana. 


\section{Ultrasonic Inspection}

UT was performed in the annulus of AY-101 in early and mid- 2001 and in 2002. UT inspection uses a remotely operated magnetic-wheeled crawler carrying an attached scanning bridge outfitted with ultrasonic sensors. To measure wall thickness, sound waves are input on the annulus side of the primary tank wall with a sensor, reflected from the waste side of the primary tank wall, and received by the same sensor. The travel time of the wave through the steel tank wall determines the thickness. Ultrasonic frequency provides a short wavelength that allows precise local measurements. The magnetic crawler requires a fairly flat, clean surface to operate, and the sensors must make good contact with the wall. Therefore, heavy rust deposits must be removed before UT inspection. The P-Scan Extended Arm attachment allows examination of about 12.5 inches of the inward-curving lower knuckle.

The traveling bridge on the crawler scans an area and produces a "map" of wall thickness. Most scans in AY-101 were 3.5-inches wide (in the direction of crawler travel) and 12 inches long (perpendicular to crawler travel). The image size varies, however, and some are 15 by 12 or even 30 by 12 inches. A 3.5 by 12-inch image consists of about 34,000 pixels, each measuring about 0.035 inch square. This pixel density is sufficient to resolve the configuration of the wall thinning so it can be attributed to pitting, cracking, or uniform thinning. The data are reported as a single value that is the minimum wall thicknesses observed of all pixel locations in the image. In some cases, the area as well as the depth of a larger area of thinning is reported.

UT inspections in 2001 performed several vertical scans in the annulus on the east and west sides of the tank and three horizontal scans in the annulus on the east side of the tank. One horizontal scan covered about $20 \mathrm{ft}$ of the historic waterline band. Several localized areas of significant thinning were identified on both east- and west-side tank scans. In the largest area of thinning, 0.65 by 0.65 inches $\left(0.423 \mathrm{in.}^{2}\right)$ at the 343 -inch level, the nominal 0.5 -inch wall was reduced to 0.404 inch thick, a $19.2 \%$ reduction. Numerous pit-like indications were also found. No crack-like indications were found.

The annulus was reexamined with UT after hydraulic wall cleaning in 2002, with special emphasis placed on obtaining confirmatory readings in the waterline band. Nine high-risk inspection areas were identified for testing, two corresponding to the stain locations observed on the inside of the primary tank and others identified from video after wall cleaning. The inspection showed more than seventy locations with wall thickness reductions between $10 \%$ and $17.4 \%$. One area of approximately 1 by 2 inches showed a minimum thickness of 0.399 inches (20.2\% thickness reduction). The majority of the wall thinning was in the historical waterline band. Numerous significant (thickness reduction in the range of $10 \%$ to $25 \%$ ) pitting indications were observed on the inside of the primary tank. There did not appear to be any correlation between wall thinning and the stain areas on the interior tank wall surface. No cracks were found.

\section{Extreme Value Statistics}

Though extensive compared with other DSTs, the UT inspections in AY-101 covered less than $5 \%$ of the tank wall area. Thus it is likely that locations of greater wall thinning would be 
observed if the entire surface were inspected. Extreme-value statistical analysis was used to estimate the minimum wall thickness measurement (Weier 2002). Given a data set of the UT images, each with a reported minimum wall thickness, extreme-value distributions are fit to the data and extrapolated to estimate the worst case for the entire tank.

To illustrate, assume we have minimum wall thicknesses from 90 UT images, each 12 inches wide, around the historic waterline band, and that these data can be fit with an appropriate extreme-value probability distribution (a three-parameter Weibull distribution was actually used). The 75-ft diameter tank has total circumference of about $236 \mathrm{ft}$. Therefore, 236 adjacent 12-inch-wide UT images would be required to measure the entire waterline. Extreme-value statistics assumes that the minimum wall thicknesses for each of the 236 images behave statistically like the 90 minimum thicknesses derived from actual measurements and thus follow the distribution that is fit to the data. Under this assumption, the thinnest of the 236 minimum wall thicknesses would be expected to occur at the $235 / 236=99.6$ percentile in the tail of the fitted distribution.

The minimum wall thickness predicted by this method was 0.3913 inches, which occurred in the waterline band. This value includes the estimated effect of uncertainty in the UT measurement itself at the $95 \%$ confidence level. The minimum wall thickness predicted for the rest of the plate containing the waterline was 0.4173 inch, and that of the plate below was 0.4184 inch. These minima are still well above the required wall thickness shown in Figure 2.3.

\section{Pit Depth Measurement}

The LazrLyne device was designed to measure small concave or convex surface features by projecting a bright-red stripe (the "laser line") at a 45-degree angle on the surface being viewed. When the stripe is positioned over a surface feature, it shows a visible offset in proportion to its height or depth. A micro-camera mounted above the projection of the red stripe transmits the images to a computer to determine the dimension based on system calibrations.

For use in AY-101, the device was mounted on the same crawler used for UT inspection, with some modifications. Annulus-side corrosion pit depth was measured in areas where heavy pitting was observed after cleaning. Only the worst pits, as determined by the operator from the onboard video, were measured. Because only specific deep-looking pits were selected nonrandomly, the LazrLyne data were not amenable to statistical analysis.

LazrLyne measurement scans for pit depths were made in AY-101 in 2002. The pit depths ranged from a low of 0.009 inch to a high of 0.067 inch. Interestingly, high-risk areas tended to show shallower pit depths than other areas. The maximum pit depth was found on the waterline and measured about $13.9 \%$ of the 0.5 -inch plate thickness.

\section{Wall Thickness Margin}

The wall thickness margin was determined by comparing the measured wall thickness with the minimum wall thickness required to withstand the anticipated loads on the tank. The minimum wall thickness represents the maximum amount of uniform thinning based on a 
structural analysis performed in 1996 (Ohl et al. 1996). This analysis conservatively assumed that the tank was full of waste at the maximum design temperature and specific gravity and included seismic loading representing a design basis earthquake. The observed corrosion in AY-101 was primarily in the form of small pits rather than uniform wall thinning. Except in extreme cases, the pits are relatively widely spaced, which leaves the wall essentially intact structurally. However, the evaluation of wall thickness margin very conservatively assumed uniform wall thinning equivalent to the deepest local pit.

The measured wall thickness and the minimum required thickness are plotted versus elevation in Figure 2.3. The minimum wall thickness generally decreases with elevation and is shown by the dashed line. The nominal design wall thickness is shown as the solid line. Note that the minimum wall thickness margin occurs at the 100 -inch elevation, where the plate thickness decreases from 3/4 to $1 / 2$ inch. The mean wall thickness measured by UT and the minimum thickness predicted by the extreme-value statistical analysis are shown as triangles and circles, respectively. It is clear that even the minimum predictions provide a very comfortable margin above the allowable thickness (note that the abrupt decrease in measured wall thickness below 262 inches probably represents installation of a thinner-than-nominal plate).

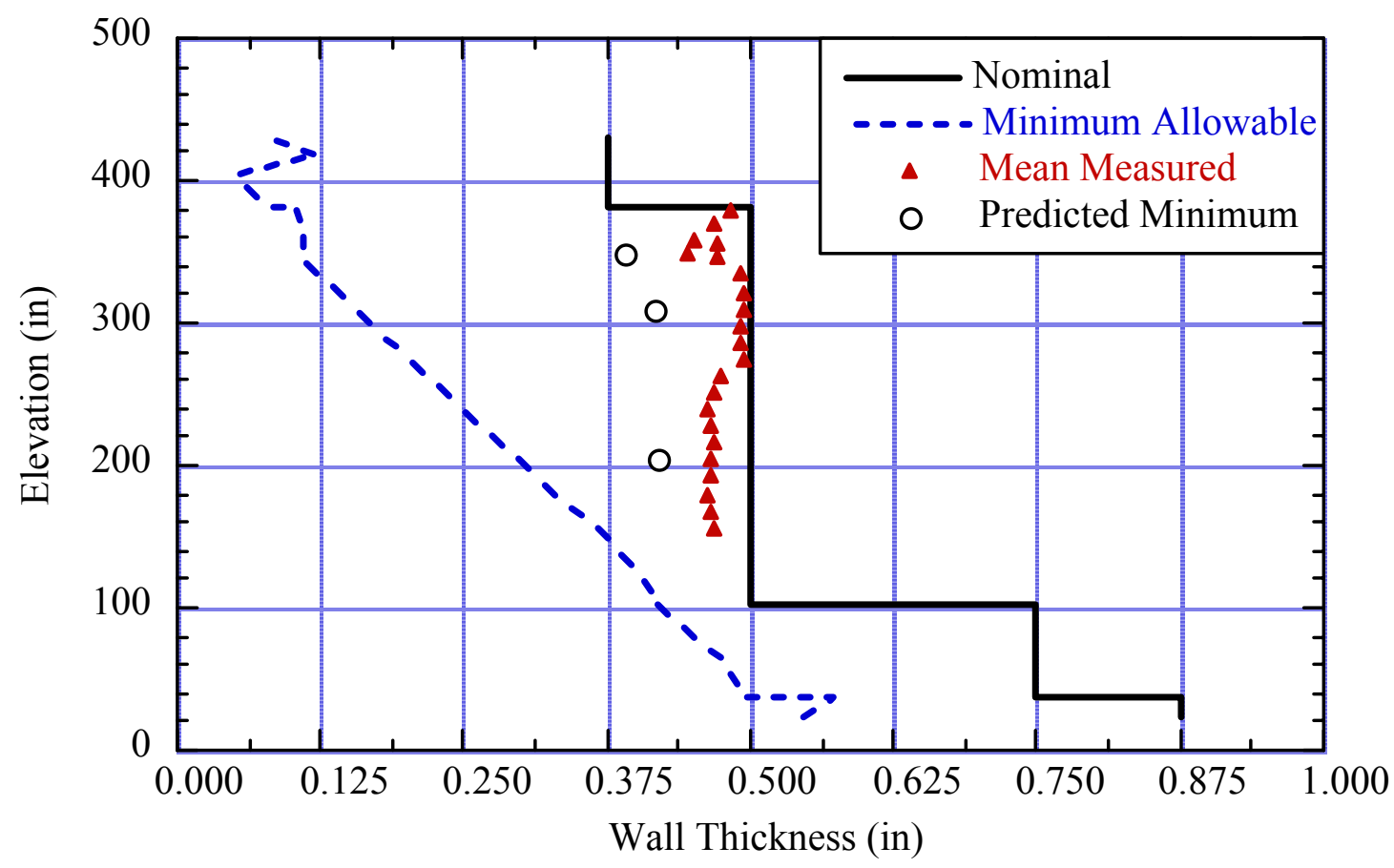

Figure 2.3. Minimum and Measured Wall Thickness in AY-101

\subsubsection{Primary Tank Leak Assessment}

As mentioned above, the most critical concern on AY-101 corrosion was the potential leak in the primary tank suggested by the stain patterns observed in the video inspection of the interior wall. However, neither the annulus leak detectors nor the continuous air monitors alarmed, so any leak that might have occurred would have been very small. Material taken from the annulus 
wall was analyzed for radioactivity, and the wall itself was tested for leaks by a gas tracer method. Results of both efforts were negative, as described below.

X-ray diffraction, wet chemical analysis, energy dispersive x-ray spectroscopy, and a microbial check were performed on samples of corrosion products taken from the AY-101 annulus (Aftanas 2001). Only corrosion products from the steel of the tank were present, and the compounds observed are consistent with steel exposed to moisture and allowed to freely corrode. No detectable radioactive contamination was found in the material. Swipes of the annulus wall in the corroded area also tested negative for radioactive contamination. The volume ratio of steel to iron oxide was determined to be almost 1:5. Therefore, what appeared to be heavy rusting in the annulus actually represented very little loss of base metal.

Tracer-gas leak testing of designated portions of AY-101 was performed in February 2002 using the hydraulic cleaning crawler as the transport vehicle. Several areas on the annulus side of the primary tank were tested, including those corresponding to the waterline stain areas. Approximately $32 \%$ of the waterline was covered. This tracer-gas test was performed by introducing a tracer gas into the primary tank headspace and collecting air samples from the line that provides the vacuum to hold the cleaning crawler to the wall. The samples were analyzed with standard gas chromatography. The analyses of the gas samples collected from locations on the annulus side of the primary tank indicated there was no leak in the area tested.

Finally, the suspect stain area on the inner wall of the primary liner was also later identified as an area that was sprayed by liquid waste when waste was being transferred into the tank. Similar stains were noted at $90^{\circ}$ intervals around the inside of the tank at about the same elevation. These corresponded to the four-jet configuration of the waste distributor that had sprayed the tank wall for some period of time. It was therefore concluded that the stains were not associated with perforations of the tank wall.

\subsubsection{Corrosion Prevention and Monitoring}

Between December 18, 2000 and January 13, 2001, 45,000 gallons of caustic were added to AY-101 to bring the waste chemistry back to within specifications. Analyses of grab samples in February 2001 and core samples obtained in April 2002 show that the waste composition was within the specified limits. The Tank Farm Authorization Basis (Cash 2000) was modified in 2000 to require that the chemistry limits be maintained as a Technical Safety Requirement (TSR). The present action plan developed by CH2M HILL (Staehr 2001) committed to bringing all tanks into chemistry control specification by September 2001 and developing a formalized chemistry surveillance program to ensure that all tanks are maintained within specifications during waste transfers or extended storage.

The annulus ventilation system was put back into operation in April 2001. Annulus ventilation operation will also be required as a TSR in double-shell tanks by an amendment to the authorization basis that is expected to be approved in 2003. A leaking valve in the raw water line was found and isolated, eliminating a probable source of raw water inleakage to the AY-101 annulus. However, it has not yet been confirmed that this was the only source of water intrusion or one of several. 
Additional UT inspections of the annulus-side of the secondary liner are planned in FY 2003 to detect any corrosion that might have occurred at the concrete-steel interface as a result of water inleakage. An unsuccessful attempt was made in December 2002 to perform a UT inspection of the tank bottom through the ventilation slots by means of a specially designed crawler. Future attempts are planned to obtain UT data on the tank bottom. 


\subsection{Primary Conclusions and Recommendations}

Based on the data presented in Berman (2002) and supporting documents that were reviewed, the review team concludes that Tank 241-AY-101 appears to be sound and fit for service without restrictions subject to the following recommendations (recommendations 3 and 4 are to be accomplished before removing the current waste level restrictions). CH2M HILL has reviewed and concurred with these recommendations, and their responses are included below (hereafter, Berman's report is referred to as RPP-13361). A copy of the letter from CH2M HILL expressing agreement with the review and committing to accomplish the recommended actions is attached as Appendix C.

1. Perform a UT inspection of the primary liner two years after the historic liquid/air interface band is re-wetted. The maximum wall thinning was found in the waterline band, where the waste level remained for long periods during the tank's 30-plus years of service. Corrosion at the liquid-vapor interface is not well understood, and there is some evidence that pitting corrosion on the interior of the primary tank could resume when re-wetted with waste, even if the waste chemistry is within specifications. Corrosion potential could be highest if the new waste level is within this band.

While the accumulated evidence does not support restricting the waste level from the historic waterline band, an early re-inspection of this area is prudent because of the uncertainty concerning liquid-vapor interface corrosion mechanisms. The UT examination should be performed two years after the historic waterline area is first resubmerged in waste, whether or not the waste level remains there. The inspection should cover the same 32 -ft by 30 -inch region of the primary liner between 321 and 351 inches, as previously inspected through riser 89 in fiscal year 2002. ${ }^{\text {(a) }}$

Using the 2002 UT data as a baseline, a comparison can be made to evaluate corrosion rates and show that the tank wall thickness remains within acceptable limits. The two-year period is believed to be sufficient to allow potential corrosion to reach detectable levels. It is also recommended that this UT inspection extend to the primary liner at the new waste level if it is above the historic waterline.

CH2M HILL response: A new Section 3.10.5 was added to RPP-13361 stating the commitment to perform a UT scan of the prior waterline defect area and sample the new waterline region 2-4 years after rewetting. Based on the current schedule for waste transfers into AY-101, this inspection is projected to occur in the fiscal year (FY) 2006 time frame.

(a) Stewart CW et al. July 2, 2002. Summary of Conclusions and Recommendations from an Independent Review of RPP-13361, "Tank 241-AY-101 Fitness for Service." Letter report TWS02.040, Pacific Northwest National Laboratory, Richland, WA. 
2. Extend the planned UT inspection of the secondary liner to include the annulus floor. Because the annulus leak detectors did not alarm, the depth of any pool of intruding water presumably stayed below about $1 / 2$ inch. However, it is likely that water inleakage wetted the annulus floor and may even have pooled locally when the ventilation system was not operating. Areas of the floor buried by debris or corrosion product that fell off the annulus walls during pressure cleaning may have remained moist much longer. Severe corrosion is possible in both scenarios, including pitting, crevice, and occluded cell corrosion. Though the secondary liner was not stress-relieved, stress corrosion cracking is very unlikely because only trace concentrations of nitrate ion would be present in water intrusion. Figure 1.1 shows the relation of the annulus floor to the primary tank and secondary liner.

The annulus floor would be the first part of the secondary liner exposed to waste leakage from the primary tank, and it is important to ensure its integrity. UT inspection should be performed on selected areas of the annulus floor corresponding to observations of significant corrosion on the walls. Inspections should check for both pitting and cracks. Though it may be difficult, inspections should include several areas that have been buried under debris or corrosion product, including a weld region if possible. The inspections need not be performed prior to removing the tank operating restrictions.

CH2M HILL response: RPP-13361 Section 3.10.1 was revised to state CH2M HILL's intent to perform UT scans of the secondary liner and annulus floor in the current fiscal year (2003). However, if the annulus floor UT encounters difficulty with debris cleanup, that portion of the work will be programmed for FY 2004.

3. Perform psychrometric analysis on the annulus exhaust to confirm absence of water inleakage. A psychrometric analysis of the annulus exhaust determined that there was approximately $40 \mathrm{gal} / \mathrm{d}$ more water in the exhaust air than in the inlet air. A leaking valve was located and isolated that was the likely source of water. However, there may be other sources of water intrusion to the annulus. The earlier intrusion may also have created preferential flow paths for rain and snow melt.

Even though analysis has shown that the annulus ventilation system can evaporate relatively high rates of water inflow, a major intrusion could continuously wet a local area of the annulus wall while it is evaporating. Thus, as part of the fitness-for-service evaluation, the absence of water inflow must be confirmed by repeating the psychrometric analysis that detected the original leak. Consideration should be given to an additional psychrometric evaluation after a large rainfall.

CH2M HILL response: A new Section 3.10.3 was added to RPP-13361 to stating that the recommended psychrometric analysis is planned for this fiscal year (FY 2003). However, $\mathrm{CH} 2 \mathrm{M}$ HILL does not consider it necessary to perform this analysis before returning AY-101 to unrestricted use. The operating annulus ventilation can evaporate 150 gallons per day of excess water, much more than the original intrusion. 
4. Verify that annulus leak detectors (including secondary leak detection wells) and CAMs are operational. Though the inspections found no leaks in the primary liner and no areas of inadequate wall thickness, the corrosion was significant, and much less than $100 \%$ of the primary liner surface was inspected. While the probability of a leak or structural failure is very small, it is prudent to ensure that leak detection systems are operational before the tank is refilled above the current 80 -inch restriction.

CH2M HILL response: A new Section 3.10.4 was added to RPP-13361 stating that Tank Farm Operations has been advised to complete an operational check of the CAMs and leak detectors before the waste level is raised above the present 80 -inch limit. This check is expected to be accomplished this fiscal year (FY 2003). 



\subsection{Recommended Revisions to RPP-13361}

The revisions recommended in this section are in addition to editorial comments transmitted separately to the author of RPP-13361. The results of further testing and analyses prescribed in recommendations 2, 3 and 4 of Section 3 will also need to be incorporated into the document when available. CH2M HILL responses to these recommendations are included.

\subsection{Water Intrusion and Annulus Ventilation}

These comments are intended to clarify the correction of the apparent dual causes of annulus corrosion, absence of annulus ventilation and water intrusion.

\subsubsection{Confirm That No Future Leak Is Possible from the Defective Valve}

RPP-13361 Section 3.6 states, "A leaking valve in the raw water line was found, and the situation was corrected, eliminating the raw water inleakage to the Tank 241-AY-101 annulus." This statement needs to be expanded to briefly describe how the leak was corrected and why no further leak is possible from this area. This should include a description of the relationship of the leaky valve to the observed annulus corrosion patterns in AY-101. The results of the psychrometric analysis (Recommendation 3 in Section 2) of the annulus ventilation exhaust to confirm that the leaking valve was the only source of water intrusion should also be presented.

CH2M HILL response: RPP-13361 Section 3.6 was expanded to describe isolation of the leaking valve (V-114) in the raw water line that was found on the west side of the tank. The leak was corrected by removing the water system supply valves for both AY-101 and AY-102 and replacing them with blind flange.

\subsubsection{Describe Potential for Water to Leak Between the Secondary Liner and Concrete Shell}

Because water apparently did penetrate into the annulus from outside, it may also have intruded between the secondary liner and the outer concrete shell. The tank design drawings and the construction method should be reviewed to determine whether such an intrusion is possible or what conditions would need to exist for it to occur. Conclusions of this investigation should be added to RPP-13361, Section 3.6.

CH2M HILL response: Section 3.6 of RPP-13361 was further expanded to state that because the concrete shell was poured against the secondary liner (i.e., secondary liner used as a casting form) it is unlikely that water intruded between the secondary liner and the concrete shell. 


\subsubsection{State Current Annulus Ventilation Rate and Evaporative Capability}

The summary section of RPP-13361 states, "The annulus ventilation system is operable and capable of significant water removal capability, which minimizes annulus corrosion." To provide a basis for this conclusion, a new paragraph should be added to RPP-13361 Section 3.6 stating the current ventilation flow rate of the restored annulus system and the estimated actual evaporative capability of that flow rate. It is also suggested that the proposed TSR requiring annulus ventilation be summarized, including required operational checks. This statement and others like it should also be revised to say that the system is now "operating," not merely "operable."

CH2M HILL response: Discussion of ventilation evaporative capability was expanded in Section 3.6 of RPP-13361, including a plot of potential moisture removal rates as a function of ventilation rate and waste temperature. For a waste temperature of $100^{\circ} \mathrm{F}$, a $1,000 \mathrm{cfm}$ ventilation flow could remove about $100 \mathrm{gal} / \mathrm{d}$ of water. Elsewhere, the annulus ventilation system is described as currently "operational."

\subsubsection{Describe Why the Annulus Ventilation System Cannot Operate if the Waste Level Is Too Low}

RPP-13361 Section 2.5 states, “... the annulus ventilation system has been inactive... because of either mechanical problems or a low liquid level in the tank, which prevents system operation." A more definitive statement is needed of what mechanical problems were corrected to restore ventilation and why the system design prevents ventilation operation at low waste levels. RPP-8474, 241-AY-101 and 241-AY-102 Annulus Primary Tank Cleaning Plan, Section 7.5, discusses this.

CH2M HILL response: Section 3.5 of RPP-13361 is expanded to explain that a floor drain line in the annulus pump pit drains into the primary tank just below the 64-inch level. If the waste level falls below the drain line opening, the drain line would provide a gas flow path from the primary tank to the annulus pit pump.

\subsection{Wall Thickness Margin}

The comments in this section strengthen the technical basis for the conclusion that the margin of actual-to-allowable wall thickness margin is more than adequate to ensure structural integrity.

\subsubsection{Describe the Structural Analyses That Are the Basis for Minimum Wall Thickness}

The last paragraph in RPP-13361 Section 3.8 states, "Assuming coincidence of the defects (i.e., 34.1 percent total wall loss), the remaining wall thickness $(0.33$ in.) is still much greater than the calculated uniform minimum wall thickness (0.114 in. from WHC-SD-WM-ER-556, Double-Shell Tank Useful Life Analysis, Table B-8) at maximum stress conditions for this tank elevation." The basis for the minimum allowable wall thickness is extremely important in 
establishing the fitness for service of AY-101 based on the UT wall thickness data. The report needs another subsection expanding the existing paragraph to discuss loads and stresses for the primary tank liner, methods for determining the acceptable levels of degradation in the form of pitting and wall thinning, and a summary of allowable levels of degradation given in the referenced Table B-8. This table should be included in RPP-13361.

The estimates of allowable degradation cited in Table B-8 appear to be based on very conservative calculations. These calculations do not take credit for the very local nature of pitting and the small area of the tank wall subject to the maximum level of thinning (this conservative connotation does not apply to cracks, though none have been detected). Resultant membrane and bending moment loads from finite element analyses were used to calculate stresses for an entire tank wall of reduced thickness. This simple approach does not exploit methods such as allowed by the ASME code to account for the local nature of the wall thinning. Such methods account for stress redistributions from a locally thinned region to adjacent regions that have no thinning. Because the levels of stress in the corroded regions of AY-101 are low, there would be no benefit gained by using these more refined methods for stress calculations.

CH2M HILL response: The last item in Section 3.8 of RPP-13361 refers the reader to Appendix F, where the minimum wall thicknesses taken from Table B-8 of WHC-SDWM-ER-556 are given along with a description of the structural analysis that produced them. A plot similar to Figure 2.3 of this report is included to compare measured wall thickness to the minimum as a function of elevation.

\subsubsection{State That High-Risk Areas Similar to Those That Couldn't Be Cleaned Were Inspected}

RPP-13361 Section 3.8.2.1 states, "One high-risk area under riser 088 in the southeast quadrant was not cleaned as expected and consequently could not be examined using the UT or LazrLyne ${ }^{\mathrm{TM}}$ equipment." A total of nine high-risk areas were identified based on the appearance of corrosion in visual inspections. To reinforce the validity of the available UT data and the extreme value statistical analysis, a discussion is needed of the similarity of the uncleaned, uninspected area to those that were inspected to ensure that no area of potentially more severe corrosion was missed.

CH2M HILL response: The first bullet in Section 3.8.2.1 of RRR-13361 is modified to defined "high-risk areas" as having heavy corrosion deposits on or near a weld, which therefore might be associated with a tank wall perforation. A statement will also be added that the one area not inspected was not likely to be different from the eight others examined based on visual appearance and inspection results.

\subsubsection{Clarify That the Waterline Is a Band, Not a Level}

The summary of RPP-13361 states, "UT data revealed corrosion patterns that correlate with the deposits at the 343-in. level, found during the vapor space visual examination. This corrosion band is considered to be waterline corrosion at the 343 -in. waterline region...." Throughout the rest of the report the historic liquid/air interface is referenced as "the 343-inch 
waterline." However, the data clearly show that the waste level varied from about 320 to 360 inches, which corresponds to the band of maximum wall thinning observed in the UT data.

A more detailed discussion of the historic waterline needs to be added, probably in Section 2.6 on waste level history, making it clear that the historic waterline is a rather wide band. It is also suggested to replace Figure 5 with Figures A.4 and/or A.5 from Appendix A of this report, which extends back to the first fill. This clarification on the extent of the waterline needs to be carried through the rest of the document.

CH2M HILL response: The term "343-in. waterline" has been generally replaced throughout RPP-13361 by "321 - 351 inch waterline band" or similar terminology.

\subsection{Leak Testing and Leak Indications}

The primary visual indication of a possible leak was the stain pattern on the interior of the primary tank that has since been attributed to transfer operations. The two comments in this section seek a more complete explanation of these operations and the qualifications of the personnel performing gas tracer testing confirming that the stain pattern was not evidence of a leak.

\subsubsection{Determine Personnel Qualifications and Standards Used in Tracer Gas Testing}

Tracer Research Corporation provided tracer-gas leak testing of designated areas of the primary liner under a contract with Oceaneering International, Inc., using the cleaning crawler as the transport vehicle for leak testing. Oceaneering personnel trained by Tracer Research Corporation collected the samples that were then transferred to Tracer Research Corporation for analysis.

Tracer testing in AY-101 was a unique application in a challenging environment that required considerable ingenuity to accomplish. Standard "cookbook" procedures probably were of little value. Nevertheless, we suggest that it would enhance the credibility of the test results if Oceaneering test personnel or those from Tracer Research who trained them were certified by a national organization such as ASNT (American Society for Nondestructive Testing). The standards (e.g., ASTM), if any, that were used for designing the test procedure should be given. This information should be researched and positive results stated in RPP-13361 Section 3.7.

CH2M HILL response: Tracer Research Corporation did not respond to CH2M HILL requests for the above information. No statement on standards used or personnel qualification can be made. 


\subsubsection{Expand Discussion Attributing Interior Stains to Waste Transfer Operation}

One of the main drivers for performing a tracer test was the appearance of a stain on the primary tank interior wall in an area where visually severe corrosion was observed on the annulus side. The interior stain had the appearance of being caused by annulus water being pulled through a tank wall perforation into the tank interior (i.e., potential pinhole leak).

RPP-13361 Section 3.5 explains the stain as follows: "Note, however, that subsequent internal visual examination (RPP-8474, 241-AY-101 and 241-AY-101 Annulus Primary Tank Cleaning Plan, Rev.1) detected three (3) additional stains at about 90 degrees from each other and the aforementioned 343-in. stain. This new indication suggested that the stains were an artifact of a spray pattern and not the result of tank perforation." More information about the actual waste transfer operation and equipment is needed to validate this conclusion. The author states that this information is available and will be added to the current explanation.

CH2M HILL response: RPP-13361 Section 3.5 was expanded to describe the basis of the staining hypothesis. Three additional stains appearing to be almost identical in size and shape were found at about the same elevation approximately 90 degrees from each other. It was postulated that the stains were caused by the four streams from the movable slurry distributor that hit the tank wall at about 340 inches, 90 degrees apart.

\subsection{Waste Chemistry Correction}

The summary of RPP-13361 Section 3.5 states that AY-101 waste chemistry was out of specification for more than seven years prior to caustic addition in January 2001, which brought it back within specifications. There is no mention of when the waste went out of specification in the waste chemistry history presented in Section 2.7, but it does state that, "In December 2000 and January 2001, $170 \mathrm{~kL}$ (45 kgal) of caustic were added to Tank 241-AY-101 to bring it into specification."

Because maintaining acceptable waste chemistry is essentially the only preventative for primary-side corrosion, it is important to validate this statement. It is recommended that the referenced statement be expanded to include the method of caustic addition and describe the post-correction waste sample composition in relation to the actual waste chemistry requirements in terms of $\mathrm{pH}$ and concentrations of hydroxide, nitrate, and nitrite ions. Core sample analysis results showing high $\mathrm{pH}$ in the sludge after caustic addition should be presented to allay concerns expressed about potential isolation of the sludge layer from caustic added to the supernate. It would also be helpful to identify which waste addition likely caused the waste to go out of specification (i.e., the starting point of the seven-year out-of-specification period) and when it occurred.

CH2M HILL response: Section 2.7 of RPP-13361 was expanded to describe May 2002 sampling and analysis results in terms of $\mathrm{pH}$ and concentrations of hydroxide, nitrate and nitrite of both the supernate and sludge. These concentrations are within the waste chemistry specifications. 


\subsection{Tank Bottom Inspection}

RPP-13361 Section 3.10.2 describes the need for primary tank bottom inspection as follows: “... the tank bottom plate... presumably was subject to corrosion from the annulus side, caused by the inoperative annulus ventilation system and the raw water intrusion... the lower plate of the tank might have been subject to wet or very high humidity conditions for several years. Although the bottom plate is low stress and quite thick (1-in.-thick x 4-ft-diameter center plate, transitioning to an 0.375 -in. plate and then to a 0.875 -in. curved knuckle plate), the possibility of deep pitting or significant thinning needed to be explored."

Unfortunately, recent attempts to obtain UT measurements of the tank bottom through the cooling slots have failed, and it is likely that future attempts may also be unsuccessful. The review team believes that tank bottom UT data are very important and that efforts to obtain them should continue. However, there are a number of mitigating factors that reduce the concern somewhat if measurements ultimately cannot be performed. They include the following:

- The primary tank bottom is about 12 inches above the annulus floor and could not have been exposed to a water pool if the leak detectors, which are $1 / 2$ inch off the floor, did not alarm.

- The tank bottom is exposed to hot waste; above it, moisture intruding from the sidewalls would tend to evaporate before it migrated any distance inward, even with ventilation inoperative.

- The tank bottom is a low-stress region with a required minimum thickness of less than 0.25 inches, according to Table B-8 of WHC-SD-WM-ER-556.

- Available data indicate that sludge corrosion is less aggressive than supernate. Experience at the Savannah River Site agrees with this. The corrosion potential measured in AY-102 sludge samples was extremely low, even when the sample was driven out of specification. Electrochemical noise probes removed from DSTs showed $0.06 \mathrm{mil} / \mathrm{yr}$ bulk thinning where they were exposed to sludge.

- AY-101 UT data on the plate immediately above the knuckle but still exposed to sludge on the primary side showed no significant corrosion.

- Video inspection does not show visually severe corrosion on the visible exterior portion of the lower knuckle.

- UT data obtained with the P-Scan Extended Arm on a 20-ft length of the knuckle in AW-102 did not show significant corrosion (although the waste differs from AY-101).

We recommend that a similar list of mitigating factors be included in the discussion of Section 3.10.2, whether or not tank bottom UT data are forthcoming.

CH2M HILL response: Tank bottom plate inspections are still being pursued intently and CH2M HILL did not deem it necessary to state these mitigating factors in RPP-13361 at this time. 


\subsection{Conclusion}

Early video evidence of apparently severe corrosion ultimately proved to be much more benign than it looked because rust occupies a much larger volume than the iron consumed. The data obtained in 2001 and 2002 show that neither the structural nor the containment integrity of the primary tank has been compromised, and the tank is fit for service. The PNNL independent review documented in this report supports this conclusion.

However, the initial concern that a million-gallon tank might have to be removed from service was a powerful wake-up call to take better care of the existing 28 DSTs. The tank farm authorization basis now requires that the chemistry limits be maintained or adjusted to prevent corrosion on the inside of the primary tank as a Technical Safety Requirement (TSR). Operation of annulus ventilation to prevent condensation and the resulting corrosion on the outside of the primary tank will also soon be a TSR in double-shell tanks. These steps, along with recurring visual and UT inspections, should prevent similar corrosion from developing in the future. 



\subsection{References}

Aftanas BL. 2001. Evaluation of 241-AY-101 Corrosion Products Risers 78 and 85. RPP-8737, CH2M HILL Hanford Group, Inc., Richland WA.

Anantatmula RP, EL Dalpiaz, EA Fredenburg, DM Ogden, and MJ Thurgood. 2001. DoubleShell Tank Annulus Ventilation Engineering Study. RPP-7695, CH2M HILL Hanford Group, Richland, WA.

Berman HS. 2002. Tank 241-AY-101 Fitness for Service. RPP-13361, CH2M HILL Hanford Group, Inc., Richland, WA.

Cash RJ. 2000. Tank Farms Final Safety Analysis Report (FSAR). HNF-SD-WM-SAR-067, CH2M HILL Hanford Group, Inc., Richland, WA.

Fort LA, DA Reynolds, KG Carothers, MA Knight, and MJ Klem. 2001. Technical Basis for Chemistry Control Program. RPP-7795, CH2M HILL Hanford Group, Richland, WA.

Ohl PC, MG Awadalla, RP Anantatmula, CE Jensen, FG Abatt, LJ Julyk and LD Muhlstein. 1996. Double Shell Tank Useful Life Analysis. WHC-SD-WM-ER-556, Westinghouse Hanford Company, Richland, WA.

Staehr TW. 2001. Double-Shell Tank Integrity Program Plan. RPP-7574, Cogema Engineering Corp., Richland, WA.

Stewart CW, SH Bush, HS Berman, CJ Czajkowski, JR Divine, GJ Posakony, AB Johnson, MR Elmore, DA Reynolds, RP Anantatmula, RL Sindelar, PE Zapp. 2001. Expert Panel Recommendations for Hanford Double-Shell Tank Life Extension. PNNL-13571, Pacific Northwest National Laboratory, Richland, WA.

Weier DR. 2002. Statistical Analysis of AY-101 Ultrasonic Measurements of Wall Thickness. PNNL-14106, Pacific Northwest National Laboratory, Richland, WA. 
Appendix A

Tank AY-101 History 


\section{Appendix A \\ Tank AY-101 History}

This appendix is adapted from the AY-101 Tank Characterization Report (TCR) and other data available through the Tank Waste Information Network System (TWINS) at Hanford. The TWINS web site is http://twins.pnl.gov:8001/twins3/twins.htm.

The AY and AZ Tank Farms were constructed between 1968 and 1970 in the Hanford 200 East Area to store highly radioactive aging waste from the PUREX plant. The AY tank farm contains two double-shell tanks (DSTs), each with a capacity of 3,785 kL (1,000 kgal), a

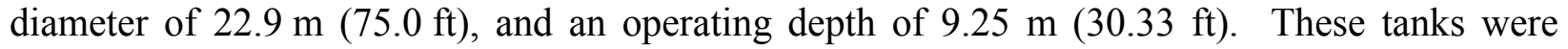
designed to hold boiling waste with a high heat-generation rate at a maximum design temperature of $177^{\circ} \mathrm{C}\left(350^{\circ} \mathrm{F}\right)$ for sludge and $127^{\circ} \mathrm{C}\left(260^{\circ} \mathrm{F}\right)$ for liquid (Brevick et al. 1995).

AY-101 was constructed with a primary carbon steel liner (heat-treated and stress-relieved), a secondary carbon steel liner (not heat-treated), and a reinforced concrete shell. The bottom of the primary liner is $9.5 \mathrm{~mm}(0.375 \mathrm{in}$.) thick; the lower portion of the sides is $19 \mathrm{~mm}(0.75 \mathrm{in}$.) thick; the upper portion of the sides is $13 \mathrm{~mm}(0.5$ in.) thick; and the dome liner is $9.5 \mathrm{~mm}$ $(0.375$ in.) thick. The secondary liner is $6.35 \mathrm{~mm}(0.25 \mathrm{in}$.) thick. The concrete walls are $457 \mathrm{~mm}(1.5 \mathrm{ft})$ thick, and the dome is $381 \mathrm{~mm}(1.25 \mathrm{ft})$ thick.

The tank has a flat bottom. An insulating concrete layer separates the bottoms of the primary and secondary liners. There is a grid of drain slots in both the insulating concrete layer and the concrete foundation beneath the secondary steel liner. The function of the grid in the concrete between the primary and secondary liners is to allow air circulation for cooling and to drain any leakage from the primary tank to leak detectors in the annulus. The grid's function in the foundation is to collect any waste that might leak from the tank and divert it to the leak detection well (Leach and Stahl 1993).

AY-101 is rare in being designed to store highly radioactive aging waste generated at the PUREX Plant. These tanks have a special support system to allow them to store and concentrate high heat-generating wastes with minimum probability of loss of integrity. The support system includes a tank preheating system comprising a steam coil, a waste mixing system composed of 22 airlift circulators, and an exhaust condenser system to control condensation in the exhaust stream. The only DSTs containing these systems are AY-101, AY-102, AZ-101, and AZ-102.

A major upgrade was made to the primary ventilation system of the AZ/AY tank farm in 1998. This included a new stack, ventilation fans, emission control equipment, emission monitoring equipment, and connecting piping (DOE-RL 1998). In addition, this modification allows for an increased airflow rate from 850 to $1,050 \mathrm{cfm}$ in AY-102. Annulus ventilation in the AY and AZ farms must be shut down if the liquid in a tank drops below 64 inches (Bergman 2000) because there is a drain path from the annulus pit to the primary tank at this level, which, if uncovered, could allow contaminated vapor to be drawn into the annulus by the annulus ventilation system. 
Figure A.1 is a plan view of the tank with all risers shown. The accompanying Table A.1 lists the risers (with both the old and new riser numbering system) and describes their use as of 2001. Figure A.2 is a section view of the tank. Note that Figure A.1 uses the old riser numbers while Figure A.2 uses the new ones.

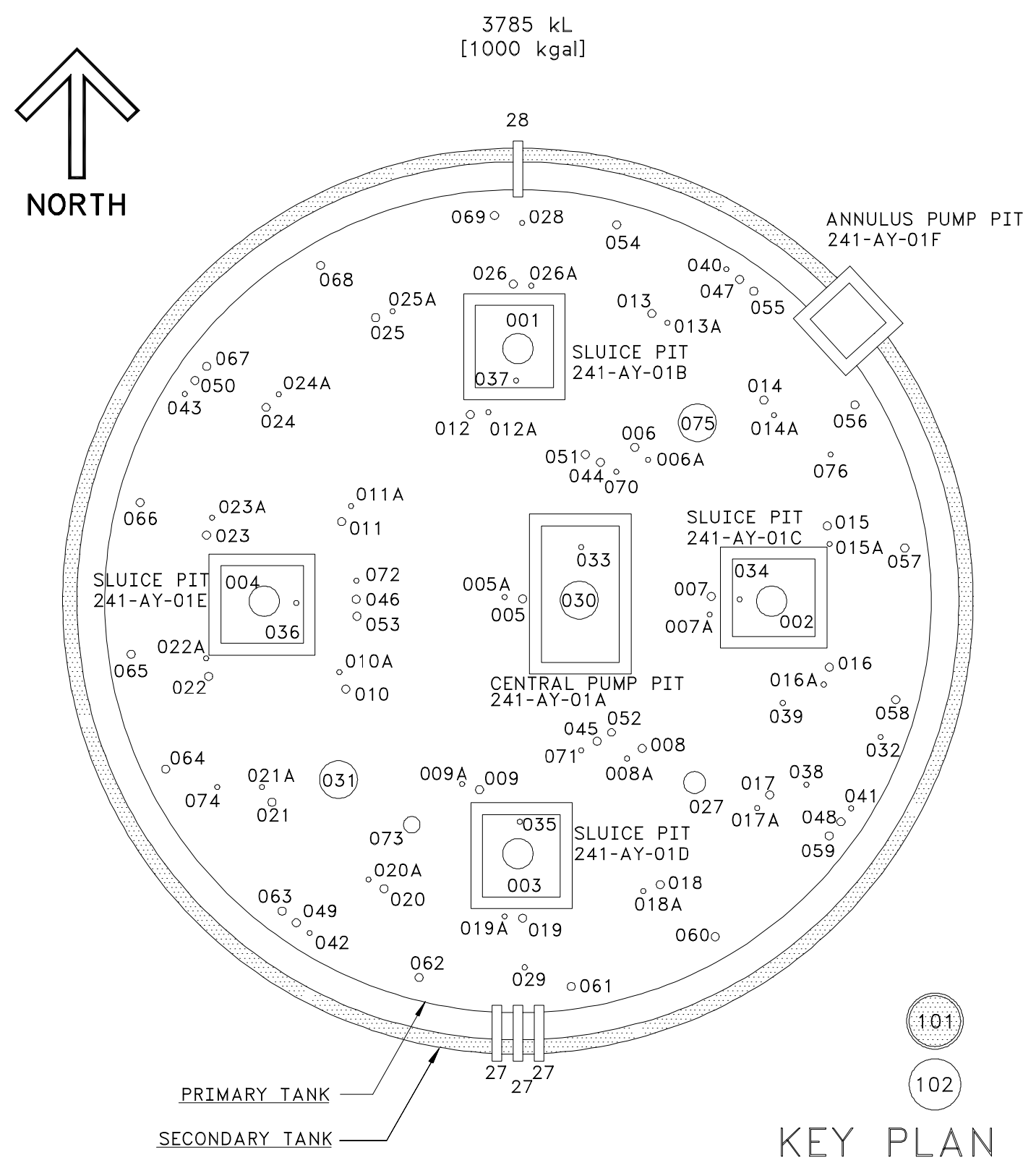

Figure A.1. Tank AY-101 Plan View and Riser Map 
Table A.1. Tank AY-101 Risers

\begin{tabular}{|c|c|c|c|}
\hline $\begin{array}{c}\text { New Riser } \\
\text { Number }\end{array}$ & $\begin{array}{l}\text { Old Riser } \\
\text { Number }\end{array}$ & $\begin{array}{c}\text { Diameter } \\
\text { (Inches) }\end{array}$ & Description and Comments \\
\hline 001 & $1 \mathrm{C}$ & 34 & Sluice pit 01B \\
\hline 002 & $1 \mathrm{~B}$ & 34 & Sluice pit 01C \\
\hline 003 & $1 \mathrm{~A}$ & 34 & Sluice pit 01D \\
\hline 004 & 1D & 34 & Sluice pit 01E \\
\hline $005-026$ & 2 & 6 & 22 Air lift circulators \\
\hline $005 \mathrm{~A}-026 \mathrm{~A}$ & 3 & $3 / 4$ & 22 Air lift circulator thermocouples \\
\hline 027 & $4 \mathrm{~A}$ & 20 & Primary tank ventilation outlet \\
\hline 028 & $5 \mathrm{~A}$ & 4 & Spare \\
\hline 029 & $5 \mathrm{~B}$ & 4 & Primary tank pressure \\
\hline 030 & $6 \mathrm{~A}$ & 42 & Central pump pit 01A riser \\
\hline 031 & $7 \mathrm{~A}$ & 42 & Steam coil heater (inactive) \\
\hline 032 & $8 \mathrm{~A}$ & 2 & Condensate addition \\
\hline 033 & $9 \mathrm{~A}$ & 4 & Pump pit 01A drain \\
\hline 034 & 10B & 3 & Sluice pit 01C drain \\
\hline 035 & $10 \mathrm{~A}$ & 3 & Sluice pit 01D drain \\
\hline 036 & 10D & 3 & Sluice pit 01E drain \\
\hline 037 & $10 \mathrm{C}$ & 3 & Sluice pit 01B drain \\
\hline 038 & $11 \mathrm{~A}$ & 4 & Leak detection pit drain / spare \\
\hline 039 & $12 \mathrm{~A}$ & 4 & High-level probe - manual tape \\
\hline 040 & $13 \mathrm{~A}$ & 4 & Thermocouple probe \\
\hline 041 & $13 \mathrm{D}$ & 4 & Thermocouple probe \\
\hline 042 & $13 \mathrm{C}$ & 4 & Thermocouple probe \\
\hline 043 & $13 \mathrm{~B}$ & 4 & Thermocouple probe \\
\hline 044 & 14B & 6 & Dry well \\
\hline 045 & $14 \mathrm{~A}$ & 6 & Dry well \\
\hline 046 & $14 \mathrm{C}$ & 6 & Dry well \\
\hline 047 & $14 \mathrm{E}$ & 6 & Dry well \\
\hline 048 & 14D & 6 & Dry well \\
\hline 049 & $14 \mathrm{G}$ & 6 & Dry well \\
\hline 050 & $14 \mathrm{~F}$ & 6 & Dry well \\
\hline 051 & $15 \mathrm{~B}$ & 6 & Sludge measurement port \\
\hline 052 & $15 \mathrm{~A}$ & 6 & Spare \\
\hline 053 & $15 \mathrm{C}$ & 6 & Standard hydrogen monitoring system vapor probe \\
\hline
\end{tabular}


Table A.1 (contd)

\begin{tabular}{|c|c|c|l||}
\hline $\begin{array}{c}\text { New Riser } \\
\text { Number }\end{array}$ & $\begin{array}{c}\text { Old Riser } \\
\text { Number }\end{array}$ & $\begin{array}{c}\text { Diameter } \\
\text { (Inches) }\end{array}$ & \multicolumn{1}{|c|}{ Description and Comments } \\
\hline 054 & $15 \mathrm{~K}$ & 6 & Sludge measurement port \\
\hline 055 & $15 \mathrm{~J}$ & 6 & Sludge measurement port \\
\hline 056 & $15 \mathrm{I}$ & 6 & Spare \\
\hline 057 & $15 \mathrm{H}$ & 6 & Spare \\
\hline 058 & $15 \mathrm{G}$ & 6 & Spare \\
\hline 059 & $15 \mathrm{~F}$ & 6 & Sludge measurement port \\
\hline 060 & $15 \mathrm{E}$ & 6 & Sludge measurement port \\
\hline 061 & $15 \mathrm{D}$ & 6 & Spare \\
\hline 062 & $15 \mathrm{~S}$ & 6 & $\begin{array}{l}\text { Sludge measurement port / primary tank pressure } \\
\text { indicator }\end{array}$ \\
\hline 063 & $15 \mathrm{R}$ & 6 & Primary tank vent inlet \\
\hline 064 & $15 \mathrm{Q}$ & 6 & Spare \\
\hline 065 & $15 \mathrm{P}$ & 6 & Spare \\
\hline 066 & $15 \mathrm{O}$ & 6 & Sludge measurement port \\
\hline 067 & $15 \mathrm{~N}$ & 6 & Sludge measurement port \\
\hline 068 & $15 \mathrm{M}$ & 6 & Spare \\
\hline 069 & $15 \mathrm{~L}$ & 6 & Spare \\
\hline 070 & $16 \mathrm{~B}$ & 4 & Sludge thermocouple \\
\hline 071 & $16 \mathrm{~A}$ & 4 & Sludge thermocouple \\
\hline 072 & $16 \mathrm{C}$ & 4 & Sludge thermocouple \\
\hline 073 & $22 \mathrm{~A}$ & 16 & Tank liquid level indicating transmitter (Enraf) \\
\hline 074 & $23 \mathrm{~A}$ & 4 & Tank level indicator - manual tape \\
\hline 075 & $24 \mathrm{~A}$ & 42 & Primary tank vent recirculation inlet / spare \\
\hline 076 & $30 \mathrm{~A}$ & 4 & Annulus pump pit 01F drain/annulus pump discharge \\
\hline $\mathrm{n} / \mathrm{a}$ & 27 & 4 & Product supply (three lines) \\
\hline $\mathrm{n} / \mathrm{a}$ & 28 & 4 & Product spare \\
\hline
\end{tabular}




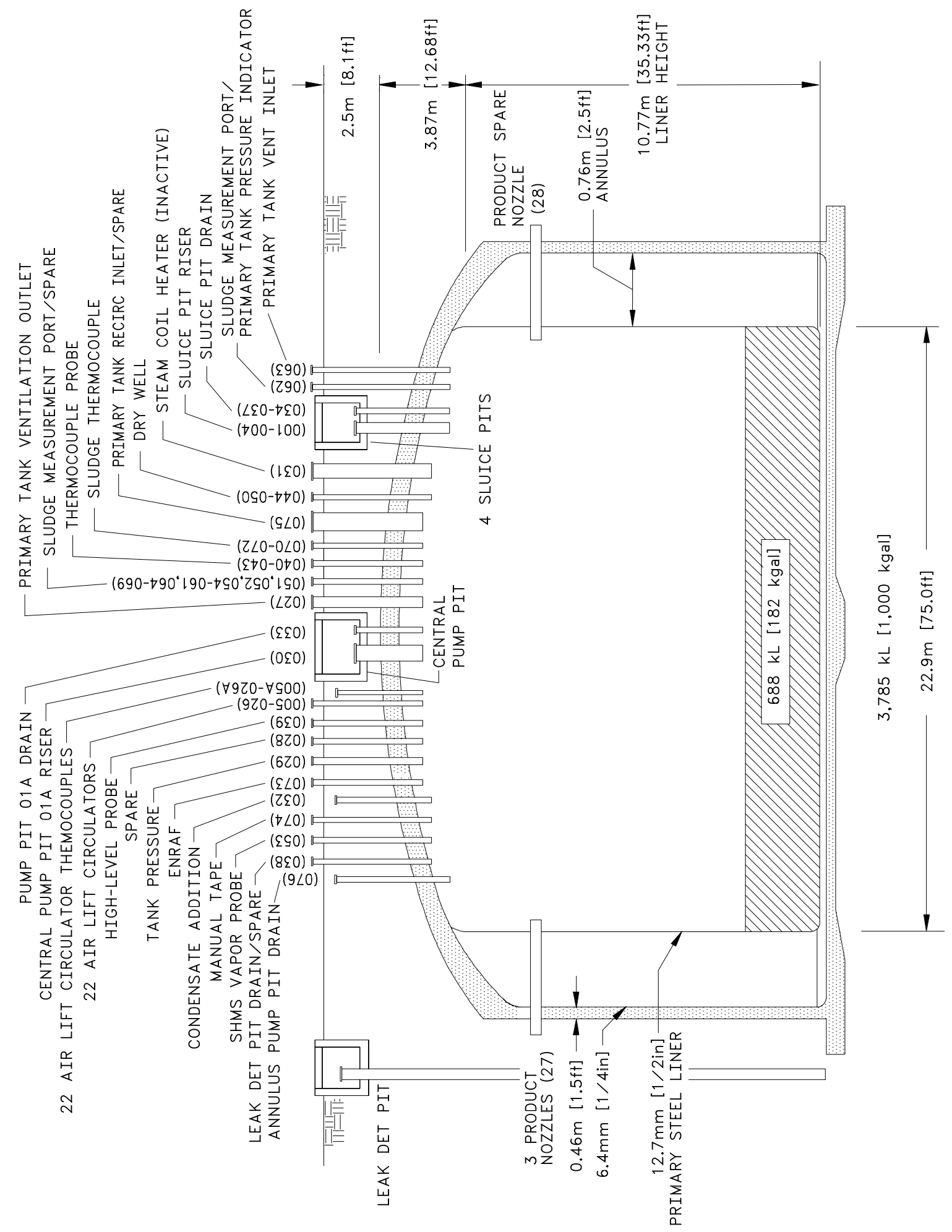

Figure A.2. Tank AY-101 Section View 


\section{A.1 Fill History}

AY-101 began receiving waste in April 1971 with the addition of high-level waste (HLW) from B-Plant. A small amount of HLW from the plutonium uranium extraction plant (PUREX) and a significant amount of PUREX waste from A-106 were added in the second quarter of 1971. AY-101 continued to receive B-Plant and PUREX waste, and excess amounts were transferred to A-106 through the fourth quarter of 1971.

Small transfers from catch AZ-152 occurred during the fourth quarter of 1974, followed by the addition of slurried PUREX sludge processed through B-Plant (SRR) during the second quarter of 1975. The waste in the tank was categorized as aging waste during the third quarter of 1976. Waste was sent to C-105 from the fourth quarter of 1977 until the second quarter of 1978 , when AY-101 was pumped down to nearly one-fifth of its total capacity. From the second quarter of 1978 until the third quarter of 1980, noncomplexed waste was received from and returned to A-102. This action most likely occurred to support 242-A Evaporator operations. Also, during the first quarter of 1980, complexed concentrate waste was transferred from A-103 to AY-101. AX-102 sent complexed concentrate waste to AY-101 during the second and third quarters of 1980.

Beginning in the first quarter of 1981 and continuing until the third quarter of 1984, AY-101 received both complexed and noncomplexed waste from cesium processing in B-Plant. During the third quarter of 1981, AY-101 sent waste out to AW-104, and in the fourth quarter of 1982, to AW-102. AY-101 also received waste from and sent waste to AZ-102 during the fourth quarter of 1983 and the first quarter of 1984. Waste was sent to AW-102 during the first and second quarters of 1984. A small addition of dilute noncomplexed waste from miscellaneous PUREX waste streams was added to AY-101 during the final quarter of 1984.

During the fourth quarter of 1984 and the first and second quarters of 1985, AY-101 began receiving dilute complexed waste from strontium processing in B-Plant. Also, waste from AW-102 was added in the first quarter of 1985. Minor water additions occurred during the span of cesium and strontium processing waste inputs. AY-101 received the last addition of dilute, complexed waste from cesium processing in B-Plant during the third quarter of 1985.

In the second and third quarters of 1986, AY-101 received dilute, complexed waste from vessel cleanouts in B-Plant and liquid waste from the saltwell pumping of Tank B-103 in the third quarter of 1986. The 242-A Evaporator sent a small amount of complexed saltwell liquid waste to AY-101 during the fourth quarter of 1991. AY-101 also received laboratory waste additions originating from the 300 and 400 Areas during the fourth quarter of 1991 and the first quarter of 1993. In August and September of 1997, 2,820 kL (745 kgal) of supernatant from AY-101 was sent to AW-102 in support of the 242-A Evaporator campaign 97-2 (Le 1997).

AY-101 has an operating capacity of $3,785 \mathrm{~kL}(1,000 \mathrm{kgal})$. The tank currently contains a small supernatant layer overlying sludge consisting of several thin layers of solids, including sludge waste from the strontium recovery operations in B-Plant, cesium recovery waste from B-Plant, B-Plant low-level waste (LLW), an unknown waste layer, PUREX HLW, and B-Plant HLW, which is expected to be on the tank bottom (Agnew et al. 1997). 
AY-101 was treated for a caustic deficiency in December 2000 and January 2001 when $170 \mathrm{~kL}$ (45 kgal) of caustic were added. ${ }^{\text {(a) }}$ AY-101 is active, categorized as sound, and not on any Watch List.

\section{A.1.2 Sampling History}

Ten grab samples and one field blank were collected from AY-101 in February 1996 (Esch 1996). These samples consisted of three supernatant and two sludge samples collected from riser 15K on February 20 and 21, 1996 and five supernatant samples collected from riser $15 \mathrm{~S}$ on February 28, 1996. The TSAP (Thompson 1996a) specified that three supernatant samples and two sludge samples would be taken from riser $15 \mathrm{~S}$, but visual inspection revealed less than $1 \%$ settled solids in the bottom two grab samples; the samples were expected to be sludge. As a result, the laboratory was directed to analyze the samples from riser $15 \mathrm{~S}$ as supernatant samples (Esch 1996). The sampling bottles were $120 \mathrm{~mL}$ in size, and full recovery was obtained from all samples.

Four supernatant grab samples and one sludge grab sample were collected from riser $15 \mathrm{~K}$ on April 21, 1997. Eight supernatant grab samples and one sludge grab sample were collected from riser $15 \mathrm{G}$ on April 22, 1997. Approximately $125 \mathrm{~mL}$ was recovered for each of the liquid grab samples and $50 \mathrm{~mL}$ for each of the two sludge samples. Settled solids of 30 to $45 \%$ were noted for the sludge grab samples.

Cores 275 and 276 were both taken from riser $15 \mathrm{G}$, where the offset riser flange was rotated $180^{\circ}$ to reposition the drill string on the opposite side of the riser between the two sampling events. Cores 277 and 278 were taken in the same manner from riser 150. Sample recovery averaged 92\%; however, it should be noted that only 6.25 inches of solids was extruded from core 277, segment 3 . The stroke length recorded during sampling for core 277 segment 3 was 17 inches (see Core Profile standard report).

Composites were made from a portion of the 2000 sample material to better characterize the waste during mixing and retrieval activities. Individual composites were prepared for cores 276 and 278. Liquids from the core were mixed with the sludge and then slurried. The liquid and sludge were separated by centrifugation prior to analysis. The concentration of most constituents was higher in the core composite liquids than in the other samples of the tank supernatant. In contrast, strontium-90, cadmium, phosphorus, nitrate and tritium all had lower concentrations in the core composite liquids then the other supernatant samples. The differences between the supernatant results and the liquid composite results may be because of liquid exchange with the sludge or dissolution/precipitation reactions in the composite.

Additional sampling and analyses will be necessary to satisfy DQO requirements for this tank, because of the planned addition of Tank C-104 waste in the near future. Sampling events in support of the caustic program are planned for February and August 2001 and February 2002.

(a) Lechelt JA. January 8, 2001. "Revision to the Updated Recommendation for Addition of Catch Tank 241-AX152 Integrity Pressure Test Water and Caustic Solution to Tank 241-AY-101." Internal memorandum CL31200-00006 to RJ Brown, CH2M HILL Hanford Group Inc., Richland, WA. 


\section{A.2 Waste Characteristics}

Analytical results show that composition of the interstitial liquid is very heterogeneous in the sludge, and concentration of soluble analytes is not a good indicator of relative water content. Table A.2 compares the nitrite:nitrate ratios for each segment from the January 2000 coresampling event with the amount of drainable liquid in each segment. The segments with the most drainable liquid have the smallest nitrite to nitrate ratio, with the supernatant segments having the smallest ratio, indicating the interstitial liquid is compositionally different from the supernatant. The nitrite:nitrate ratio was smaller in retake segments than the corresponding original samples, indicating that some supernatant intruded into sludge segments during retakes.

Table A.2. Nitrite/Nitrate Concentration Ratio

\begin{tabular}{|c|c|c|}
\hline Sample Location ${ }^{(a)}$ & $\begin{array}{c}\text { Nitrite/Nitrate } \\
\text { Ratio }\end{array}$ & $\begin{array}{c}\text { Drainable Liquid } \\
\text { (g) }\end{array}$ \\
\hline AY-101 Core 275 , Segment 1 & 4.33 & 316 \\
\hline AY-101 Core 276, Segment 1 & 4.36 & 295 \\
\hline AY-101 Core 278, Segment 1 & 4.69 & 314 \\
\hline AY-101 Core 277, Segment 1 & 4.76 & 315 \\
\hline AY-101 Core 276, Segment 2R & 5.16 & 193 \\
\hline AY-101 Core 278, Segment 2R & 5.27 & 151 \\
\hline AY-101 Core 276, Segment 2 & 6.43 & 8.8 \\
\hline AY-101 Core 278, Segment 2 & 7.52 & 61 \\
\hline AY-101 Core 276, Segment 3R & 9.71 & 25 \\
\hline AY-101 Core 278, Segment 3R & 9.86 & 32 \\
\hline \begin{tabular}{|l|} 
AY-101 Core 278, Segment 3 \\
\end{tabular} & 12.04 & 21 \\
\hline \begin{tabular}{|l|} 
AY-101 Core 275, Segment 3 \\
\end{tabular} & 13.66 & 5 \\
\hline
\end{tabular}

The sludge waste heterogeneity in AY-101 is relatively unique. Analytical results from the 2000 core sampling event capture a layering effect in the solids. While the identification of the individual waste types is difficult, the heterogeneity of the sludge is apparent, as shown in Table A.3.

Shear strength measurements are important for assessing the quantity of waste retrievable by mixer pumps (Tedeschi 2000). Shear strength measurements on the 2000 core samples have been reported by Bechtold ${ }^{(a)}$ for this tank and ranged from 1 to $1,964 \mathrm{~Pa}$. The shear strength of the third (bottom) segment was consistently higher than the second (top) segment of each core. Without the aid of shear strength measurements, Grams (1995) has estimated that a $15 \mathrm{~kL}$ (4 kgal) sludge heel will remain in the tank after the waste is retrieved with a mixer pump.

(a) Bechtold DB. December 11, 2000. Shear Strengths of 241-AY-101 Sludge Samples. Internal memorandum 8D500-DBB-00-060 to KE Bell. Fluor Global Services, Richland, WA. 
Table A.3. Mean Segment Level Concentration of Selected Metals in Sludge

\begin{tabular}{|c|c|c|c|c|}
\hline Core number & Segment $^{(a, b)}$ & $\begin{array}{c}\text { Aluminum } \\
(\mu \mathrm{g} / \mathrm{g})\end{array}$ & $\begin{array}{l}\text { Iron }^{(\mathbf{c})} \\
(\mu \mathrm{g} / \mathrm{g})\end{array}$ & $\begin{array}{c}\text { Nickel }^{(\mathrm{c})} \\
(\mu \mathrm{g} / \mathrm{g})\end{array}$ \\
\hline 275 & Two, upper half & 22,300 & 41,500 & 712 \\
\hline 275 & Two, lower half & 5,355 & 127,500 & 3,610 \\
\hline 275 & Three, upper half & 78,650 & 55,500 & 3,535 \\
\hline 276 & Two unner half & 28.800 & 5650 & 719 \\
\hline 276 & Two, lower half & 43,250 & 119,000 & 3,500 \\
\hline 276 & Three, upper half & 72,650 & 50,650 & 3,055 \\
\hline 276 & Three, lower half & 55,300 & 63,150 & 4,005 \\
\hline 277 & Two, upper half & 32,150 & 46,550 & 975 \\
\hline 277 & Two, lower half & 60,350 & 118,000 & 3,600 \\
\hline 277 & Three, whole & 80,650 & 46,400 & 2,805 \\
\hline & & & & \\
\hline 278 & Two, upper half & 42,150 & 60,200 & 1180 \\
\hline 278 & Two, lower half & 56,900 & 117,000 & 3,460 \\
\hline 278 & Three, upper half & 105,500 & 60,600 & 3,515 \\
\hline 278 & Three, lower half & 67,600 & 55,450 & 3,295 \\
\hline \multicolumn{5}{|c|}{$\begin{array}{l}\text { (a) Segments are arranged from top to bottom; segment } 1 \text { was a supernatant segment for all cores. } \\
\text { (b) Retakes were not included in this table. Here, retakes are defined as samples from the same } \\
\text { riser where the drill string was not rotated } 180^{\circ} \text {. } \\
\text { (c) Acid digest, ICP analysis. }\end{array}$} \\
\hline
\end{tabular}

Until December 2000, the tank was out of specification for corrosion control because of a caustic deficiency (Jenson 1999). This deficiency was corrected by the addition of sodium hydroxide in the tank in December $2000^{\text {(a) }}$ and January 2001. (b) Grab samples were taken in February 2001 and core samples in April 2002. Analysis of these samples showed that the waste chemistry was within specification.

Aluminum in the tank apparently precipitated out of the supernatant between 1985 and 1995 , concomitant with a decrease in tank $\mathrm{pH}$ and an increase in the tank sludge level. Presumably, this aluminum precipitated as a hydroxide solid in response to the drop in tank $\mathrm{pH}$ (e.g., $\mathrm{Al}(\mathrm{OH})_{4}^{-}$(aqueous) $^{+} \mathrm{H}^{+} \rightarrow \mathrm{Al}(\mathrm{OH})_{3 \text { (solid) }}+\mathrm{H}_{2} \mathrm{O}$ ). Much of the sludge in the tank is aluminum [see Best-Basis Inventory (Non-Radionuclides) Standard Reports]. If fixing the caustic deficiency caused or will cause substantial amounts of aluminum to redissolve, as observed in

(a) Carothers KG. December 20, 2000. "Volume of Caustic Solution to Add to Tank 241-AY-101." Internal memorandum CL3120-00-016 to WJ Powell, CH2M HILL Hanford Group, Inc., Richland, WA.

(b) Lechelt JA. January 8, 2001. "Revision to the Updated Recommendation for Addition of Catch Tank 241-AX152 Integrity Pressure Test Water and Caustic Solution to Tank 241-AY-101.” Internal memorandum CL31200-00006 to RJ Brown, CH2M HILL Hanford Group Inc., Richland, WA. 
laboratory studies with AY-101 sludge, $\left({ }^{a}\right)$ the rest of the sludge phase constituents must be concentrated. Physical properties such as shear strength may be affected. Sludge level measurements show a sludge level decrease of 3.25 inches (33.8 kL; $8.9 \mathrm{kgal})$ between July 1997 and January 2001, after the caustic addition. These data do not confirm that the sludge level drop was induced by the caustic addition.

\section{A.3 Best Basis Inventory}

An evaluation of the Best Basis Inventory (BBI) for AY-101 as of January 1, 2001 was performed and is described in this section. The following information was used in this evaluation:

- AY-101 liquid grab samples from the February 1996 analyses.

- AY-101 liquid grab samples from the April 1997 analyses.

- AY-101 liquid and solid core sample results, analyzed on a segment basis, from the January 2000 core sampling event.

- AY-101 liquid and solid core sample results on the composites made from the January 2000 core sampling event.

- Supplemental data from the Hanford Defined Waste (HDW) model document (Agnew et al. 1997), which provides tank content estimates in terms of component concentrations and inventories.

The 1996 and 1997 grab sample results were only needed to create a process-knowledge vector describing the tank supernatant.

Table A.4 summarizes how the best-basis inventories for AY-101 were derived. Three waste phases were identified for the tank: supernatant, sludge-liquid, and sludge-solids. Inventories were computed for each phase separately and then summed to obtain the overall tank inventory. All inventory calculations were performed using the BBI Maintenance Tool. The updated bestbasis inventory values for AY-101 can be found in the Best-Basis Inventory (Non-Radionuclides) and Best-Basis Inventory (Radionuclides) standard reports.

Waste phase volumes for AY-101 were derived from the January 1, 2001 manual tape reading and a July 1997 sludge level measurement. As of January 1, 2001, the manual tape reading for the tank was recorded as 52.75 inches, which converts to a total waste volume of $549 \mathrm{~kL}$ (145 kgal). The surface level as of December 29, 2002 is 65.3 inches, which reflects the sodium hydroxide solution addition between December 18, 2000 and January 13, 2001. The current total sludge volume for AY-101 is $409 \mathrm{~kL}$ (108 kgal). The supernatant volume is the difference between the sludge and the total volume. Assuming an average in-tank sludge drainable liquid volume fraction of 0.15 (Fort and Ubay 2000), the volume of drainable interstitial liquid present in the tank is estimated to be $61 \mathrm{~kL}(16 \mathrm{kgal})$. The sludge-solids volume was determined by subtracting the sludge-liquid volume from the total sludge volume.

(a) Herting DL. March 12, 1996. "Caustic Demand of Sludge Sample from Tank 241-AY-101 and 241-AY-102." Internal memorandum 75764-PCS96-023 to JM Jones, Westinghouse Hanford Company, Richland, WA. 
Table A.4. AY-101 Best Basis Inventory Source Data

\begin{tabular}{|c|c|c|c|c|c|}
\hline $\begin{array}{l}\text { Waste } \\
\text { Phase }\end{array}$ & $\begin{array}{l}\text { Waste } \\
\text { Type }\end{array}$ & $\begin{array}{c}\text { Applicable Concentration } \\
\text { Data }\end{array}$ & $\begin{array}{l}\text { Associated } \\
\text { Density }\end{array}$ & Multipliers & $\begin{array}{c}\text { Associated } \\
\text { Volume }\end{array}$ \\
\hline Supernate & $\begin{array}{l}\text { Not } \\
\text { Applicable }\end{array}$ & $\begin{array}{l}\text { Estimated supernatant con- } \\
\text { centration for Jan. 1, 2001 }\end{array}$ & $1.00 \mathrm{~g} / \mathrm{mL}^{(\mathrm{a})}$ & 1.00 & $\begin{array}{l}140 \mathrm{~kL} \\
(37 \mathrm{kgal})\end{array}$ \\
\hline \multirow{3}{*}{$\begin{array}{l}\text { Sludge- } \\
\text { Liquid }\end{array}$} & \multirow{3}{*}{$\begin{array}{l}\text { Not } \\
\text { Applicable }\end{array}$} & $\begin{array}{l}\text { Mean of } 2000 \text { interstitial } \\
\text { liquid segment samples }\end{array}$ & $1.14 \mathrm{~g} / \mathrm{mL}$ & 1.00 & \multirow{3}{*}{$\begin{array}{l}61 \mathrm{~kL} \\
(16 \mathrm{kgal})\end{array}$} \\
\hline & & $\begin{array}{l}\text { Mean of } 2000 \text { liquid core } \\
\text { composite samples }\end{array}$ & $1.14 \mathrm{~g} / \mathrm{mL}$ & 1.00 & \\
\hline & & $\begin{array}{l}\text { HDW SMM }{ }^{(\mathrm{b})} \text { composite } \\
\text { inventory for AY-101 }\end{array}$ & $1.17 \mathrm{~g} / \mathrm{mL}$ & 0.731 & \\
\hline \multirow{3}{*}{$\begin{array}{l}\text { Sludge- } \\
\text { Solid }\end{array}$} & \multirow{3}{*}{$\begin{array}{l}\text { Not } \\
\text { Applicable }\end{array}$} & $\begin{array}{l}\text { Mean of } 2000 \text { core sample } \\
\text { segments }\end{array}$ & $1.59 \mathrm{~g} / \mathrm{mL}$ & 1.00 & \multirow{3}{*}{$\begin{array}{l}348 \mathrm{~kL} \\
(92 \mathrm{kgal})\end{array}$} \\
\hline & & $\begin{array}{l}\text { Mean of } 2000 \text { sludge } \\
\text { composite samples }\end{array}$ & $1.59 \mathrm{~g} / \mathrm{mL}$ & 1.00 & \\
\hline & & $\begin{array}{l}\text { HDW TLM }{ }^{(\mathrm{c})} \text { solids com- } \\
\text { posite inventory for AY-101 }\end{array}$ & $1.39 \mathrm{~g} / \mathrm{mL}$ & 0.359 & \\
\hline Total tank & & & & & $\begin{array}{l}549 \mathrm{~kL} \\
(145 \mathrm{kgal})\end{array}$ \\
\hline \multicolumn{6}{|c|}{$\begin{array}{l}\text { (a) This is a placeholder density. Density is not needed for inventory calculations for liquids. } \\
\text { (b) SMM=Supernatant Mixing Model (Agnew et al. 1997). } \\
\text { (c) TLM=Tank Layer Model (Agnew et al. 1997). }\end{array}$} \\
\hline
\end{tabular}

\section{A.4 Waste Level and Temperature History}

The waste level history for AY-101 since it was put into service in 1971 is shown in Figure A.3. The waste levels prior to 1981 were derived from the fill history. The two shaded bands in the figure indicate regions where the waste level remained for relatively long periods. These regions are loosely termed "waterlines" or "beach lines" from the similarity between the tank and a natural body of water. The water lines are more clearly visible on the distribution of cumulative time-at-level given in Figure A.4. The waste level spent 17 years in the primary "waterline" band between 318 and 362 inches and 5.6 years in a secondary, more recent band between 50 and 69 inches.

Waste temperature histories since November 2000 are shown in Figure A.5. The three thermocouples are near the base of three airlift circulators at roughly the 20 - $\mathrm{ft}$ radius and thus represent the sludge temperature. The waste temperature ranges between $90^{\circ}$ and $105^{\circ} \mathrm{F}$ with seasonal swings on the order of $5^{\circ} \mathrm{F}$. 


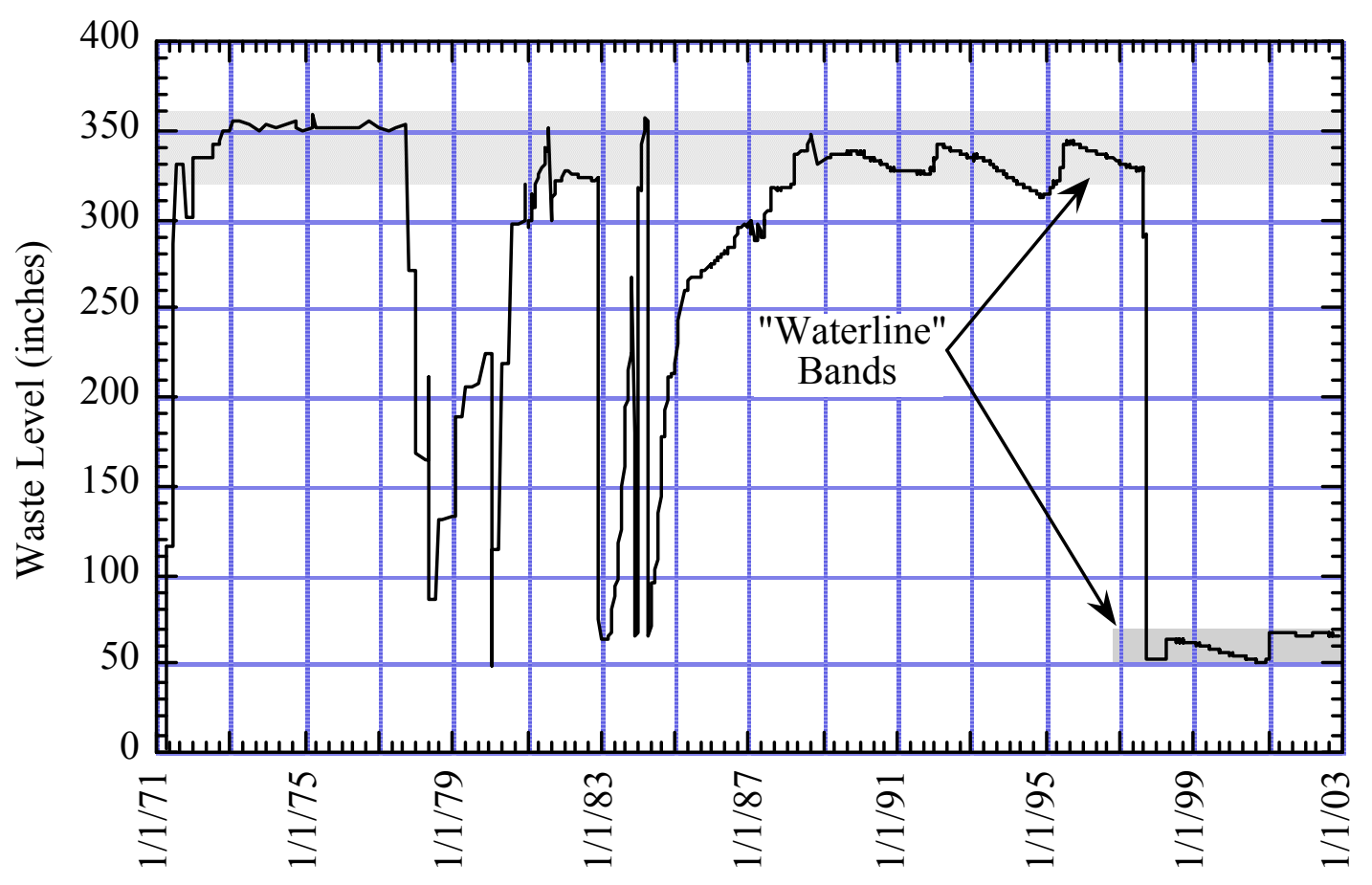

Figure A.3. AY-101 Waste Level History

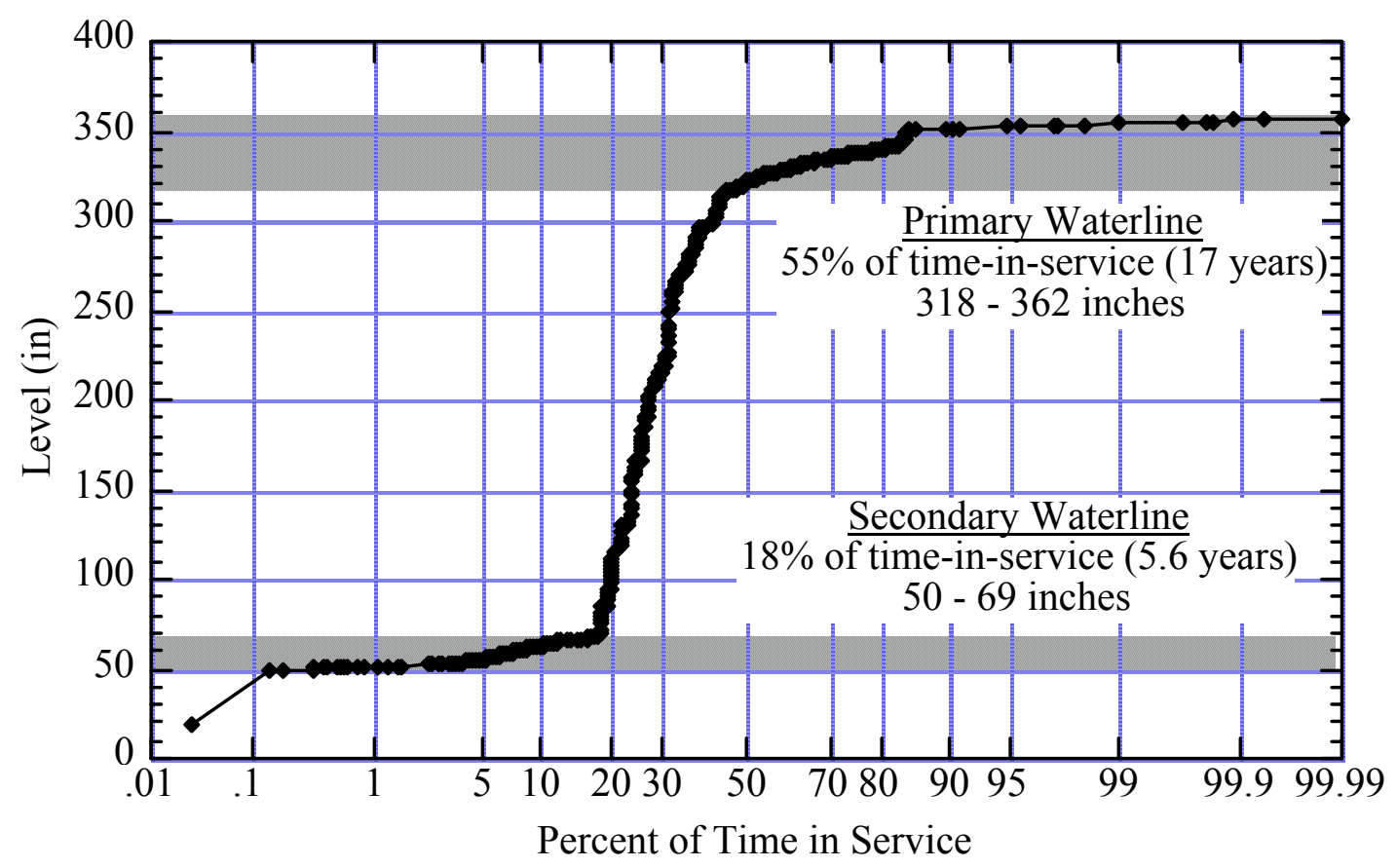

Figure A.4. AY-101 Cumulative Time-at-Level 


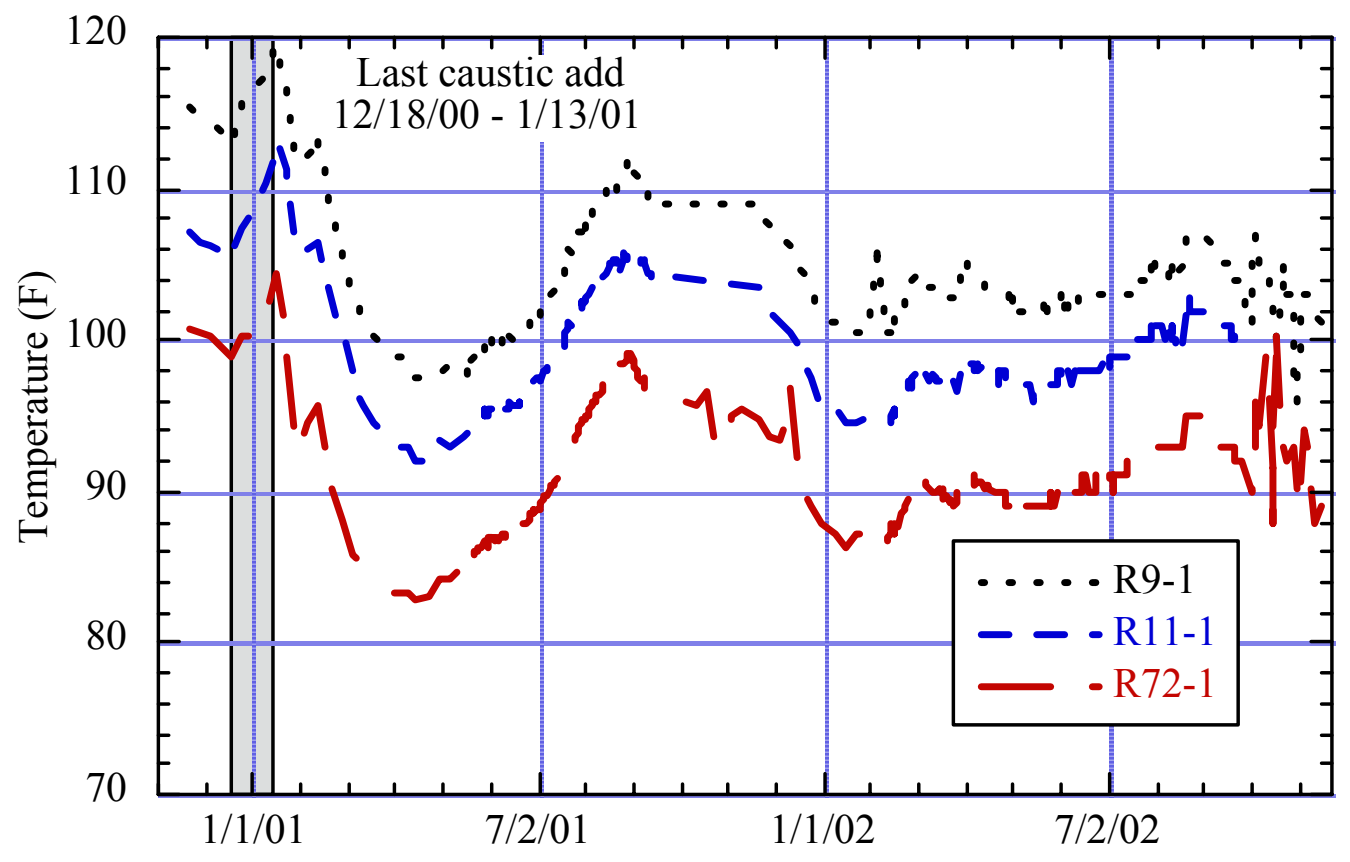

Figure A.5. AY-101 Recent Waste Temperature History

\section{A.5 References}

Agnew SF, J Boyer, RA Corbin, TB Duran, JR Fitzpatrick, KA Jurgensen, TP Ortiz, and BL Young. 1997. Hanford Tank Chemical and Radionuclide Inventories: HDW Model Rev. 4. LA-UR-96-3860, Los Alamos National Laboratory, Los Alamos, NM.

Bergman LM. 2000. Operating Specification for Aging-Waste Operations in 241-AY and 241AZ. OSD-T-151-00017 Rev. D-12, CH2M HILL Hanford Group, Inc., Richland, WA.

Brevick CH, LA Gaddis, and SD Consort. 1995. Supporting Document for the Historical Tank Content Estimate for AY Tank Farm. WHC-SD-WM-ER-317 Rev. 0, Westinghouse Hanford Company, Richland, WA.

DOE-RL. 1998. Radioactive Air Emissions Notice of Construction for Ventilation Upgrades for 241-AY and 241-AZ Tank Farms. DOE/RL-98-27 Rev. 0, U.S. Department of Energy Richland Operations Office, Richland, WA.

Esch RA. 1996. Final Report for Tank 241-AY-101, Grab Samples 1AY-96-1 Through 1AY-96-10 and 1AY-96-FB. WHC-SD-WM-178 Rev. 1, Westinghouse Hanford Company, Richland, WA. 
Fort LA and CG Ubay. 2000. Updated Drainable Interstitial Liquid Volumes Estimates and Jet Pump Durations for Interim Stabilization of Remaining Single Shell Tanks. HNF-2978 Rev.2, CH2M HILL Hanford Group, Inc. Richland, WA.

Jenson CE. 1999. 241-AY Double-Shell Tanks Integrity Assessment Report. HNF-4959 Rev. 0, Lockheed Martin Hanford Corp., Richland, WA.

Le EQ. 1997. 242-A Campaign 97-2 Process Control Plan. HNF-SD-WM-PCP-014 Rev. 0, Waste Management Hanford, Richland, WA.

Leach CE and SM Stahl. 1993. Hanford Site Tank Farm Facilities Interim Safety Basis. WHC-SD-WM-ISB-001 Rev. 0, Westinghouse Hanford Company, Richland, WA.

Tedeschi AR. 2000. Derived Requirements for Double-Shell Tank High-Level Waste Auxiliary Solids. RPP-5664 Rev. 0, CH2M HILL Hanford Group, Inc., Richland, WA. 

Appendix B

Biographical Sketches 


\section{Appendix B \\ Biographical Sketches}

\section{Dr. Spencer H. Bush}

Dr. Bush received BS degrees in Metallurgical Engineering and Chemical Engineering in 1948, an MS in Metallurgical Engineering in 1950, and a Ph.D. in Metallurgy in 1953, all from the University of Michigan.

Dr. Bush is a consultant on materials and safety with particular emphasis on environmental effects such as stress corrosion and radiation damage as they affect material properties and component design in nuclear reactors. In this capacity he has served on many of National committees and boards including the following:

- ASME: Member-at-large or ex-officio member of ASME Board of Nuclear Codes and Standards since 1983; Charter Member of ASME Subcommittee XI on in-service inspection; chaired numerous review groups.

- AEC/NRC: Member of Advisory Committee on Reactor Safeguards (ACRS) from 1966 to 1978, Chairman of ACRS 1971, consultant to the ACRS on various subcommittees; served as Vice-Chairman and Chairman of task groups on stress corrosion cracking and other pipe cracking issues, 1978 to 1987.

- DOE: Member of the Tank System Integrity Panel (TSIP), 1991-present.

- DOE/WSRP: Technical expert for Savannah River Piping and Vessels, 1992-1999.

His scientific contributions have been primarily in the physical and mechanical metallurgy of nuclear materials. Specific experimental work has been in temper embrittlement of steels, surface hardening of pearlitic malleable irons, gold base and chrome-cobalt based dental alloys. Work in reactor materials included kinetics studies of oxidation in zirconium alloys, effect of fabrication variables on properties of zirconium alloys, irradiation effects in uranium alloys and reactor structural materials, and stress corrosion. He has done substantial work in reactor safety, particularly on failure mechanisms in pressurized systems, and has also explored the field of information storage and retrieval.

A major role in Dr. Bush's career has been in the synthesis of available information to develop a coherent picture of the relative roles of materials, fabrication, and nondestructive examination on the reliability of nuclear components. Based on such a synthesis of data generated throughout the world, it is possible to suggest changes leading to an improvement in reliability with a comparable improvement in system safety. Included in such syntheses are the role of seismic loads on components and systems.

Dr. Bush was the chairman of the senior review committee tasked with evaluating the Hanford Double-Shell Tank Integrity project in May 2001. 


\section{Mr. Calvin H. Delegard}

Mr. Delegard received his BS degree in Chemistry from Washington State University and has completed graduate course work at the University of Colorado and Washington State University.

Mr. Delegard has twenty-two years of experience in applied/process chemistry and nuclear materials safeguards at the Hanford Site, including process and waste chemistry studies for plutonium separation and processing, PUREX, and the Plutonium Finishing Plant. He has been extensively involved in Hanford tank waste chemistry, studying gas generation in Tank SY-101, evaporator concentration and crystallization chemistry, and tank waste treatment chemistry. He has studied material corrosion, including corrosion of mild steel in basalt groundwater.

More recently Mr. Delegard has performed chemical characterization on $\mathrm{K}$ Basin sludges, including corrosion and resulting gas generation from uranium metal corrosion. He also served as technical liaison with the Institute of Physical Chemistry, Russian Academy of Sciences, on chemistry of the actinides and technetium in alkaline media, on $\mathrm{K}$ Basin sludge treatment and disposal and chromium phase dissolution.

Mr. Delegard also spent eight years working in the area of nuclear materials safeguards at the International Atomic Energy Agency, Vienna, Austria. This work has involved international nuclear material safeguards inspection execution, design information, and destructive and nondestructive nuclear materials verification methods development.

\section{Mr. Monte R. Elmore}

Mr. Elmore received both his BS and MS degrees in Metallurgical Engineering from South Dakota School of Mines and Technology in 1975 and 1976, respectively.

Mr. Elmore joined Pacific Northwest National Laboratory (PNNL) in September 1978. His work has principally involved corrosion testing and materials evaluation, hazardous and radioactive waste remediation investigations, and chemical process development studies. He is skilled in both bench-scale and pilot-scale experimental work and analytical evaluations and has task and project management experience.

Prior to joining PNNL, he was a research metallurgist with Duval Corporation in Tucson, Arizona, where he was engaged in research studies on ore concentrate processing and metal electrowinning, computer process simulations, and process equipment design and development.

The following list includes some of his significant technical accomplishments:

- Evaluated steel corrosion in several environments to support extension of HLW tank life for West Valley Demonstration Project.

- Evaluated materials corrosion for Hanford Waste Vitrification Project and recently for River Protection Project's Waste Treatment Plant to select suitable materials of construction for processing equipment. 
- Tested performance of nickel-plated zirconium getters for hydrogen absorption for the Tritium Target Qualification Program.

- Participated in BCD technology demonstration at Guam, building and operating off-gas analysis system to monitor PCB destruction.

- Co-developed process for acid digestion of chemical munitions that led to patent on "Munitions Treatment by Acid Digestion."

Mr. Elmore was a member of the senior review committee that evaluated the Hanford DoubleShell Tank Integrity project in May 2001.

\section{Dr. A. Burton Johnson, Jr.}

Dr. Johnson is a Senior Staff Scientist in Materials and Engineering Analysis at Pacific Northwest National Laboratory (PNNL). He received both BS and PhD degrees in Fuel Technology from the University of Utah in 1954 and 1958, respectively. The PhD included a minor in nuclear physics.

Dr. Johnson's career at PNNL has involved corrosion investigations on several metals in and out of irradiated environments. He conducted corrosion studies in aqueous and air environments that included carbon steels. He was project manager for the Nuclear Plant Aging Research program, which involved aging assessments on materials and components comprising safety-related equipment from commercial nuclear plants, again including effects of corrosion on carbon steels. $\mathrm{He}$ also participated in evaluation of a license renewal application for a commercial nuclear plant, assessing systems that included carbon steel.

Dr. Johnson chaired several committees for the National Association of Corrosion Engineers. He has been involved in a number of consultant groups and coordinated research programs for the International Atomic Energy Agency. He received the American Nuclear Society Mishima Award "in recognition of outstanding contributions in research and development work on nuclear fuels and materials." He was Inland Empire Engineer of the Year.

Dr. Johnson was a member of the senior review committee tasked with evaluating the Hanford Double-Shell Tank Integrity project in May 2001.

\section{Mr. Allan F. Pardini}

Mr. Pardini is a Senior Development Engineer at PNNL and has an MS degree in Electrical Engineering from Washington State University. He has extensive experience in nondestructive examination systems design and development. His current interests include applying cuttingedge technology to solving some of the hardest inspection problems in the environmental cleanup arena. Mr. Pardini has managed a number of NDE projects and personnel and has a diverse background including expertise in robotic and advanced vision systems. 
Mr. Pardini holds ASNT (American Society for Nondestructive Testing) Level III Certification, MT, PT, UT, ET (MM-1288). He is the author or co-author of more than 20 technical articles and publications on NDE research and applications

\section{Mr. Gerald J. Posakony}

Mr. Posakony received a BS in Electrical Engineering from Iowa State University. After working several years as a manufacturing engineer for Decimeter, Inc. and as a field engineer for Motorola, Inc., he joined the faculty of the University of Colorado Medical Center as a research engineer. He left the University to join Automation Industries, Inc., advancing to Vice President and General Manager of the Research Division in Boulder, Colorado. In this capacity, Mr. Posakony was responsible for the developmental research, instrument design, technical procedures, and manufacture of systems for nondestructive evaluation (NDE) technology in ultrasonic, eddy current, infrared, and magnetic methods.

In 1973, he joined Pacific Northwest National Laboratory (PNNL) as manager of the NDE Section, which was responsible for the design, development, and deployment of advanced NDE technology. He became manager of the Automation and Measurement Sciences Department in 1986. The staff included physicists, computer scientists, electrical and mechanical engineers, and technicians engaged in design, development and deployment of "first of a kind" inspection and measurement systems. In 1989, he became Deputy Manager of the Applied Physics Center with managerial responsibility for staff in the Automation and Measurement Science, Computational Science, and Energy Science Departments.

While officially retired from PNNL, he remains on staff as an hourly professional to continue research, development and deployment of NDE Technology. Mr. Posakony has spent more than thirty-five years in the design, development and deployment of first-of-a-kind nondestructive inspection and measurement systems. In addition to his technical and managerial responsibilities, he has continued personal research in ultrasonic transducers, inspection technology, and ultrasonic wave propagation as well as other activities in the field of NDE.

Mr. Posakony was a member of the senior review committee tasked with evaluating the Hanford Double-Shell Tank Integrity project in May 2001.

\section{Dr. Frederic A. Simonen}

Dr. Simonen, a Senior Staff Engineer at PNNL, received a BS in Mechanical Engineering from Michigan Technological University, and an $\mathrm{MS}$ and $\mathrm{PhD}$ in Engineering Mechanics from Stanford University.

Since joining Pacific Northwest National Laboratory in 1976, and earlier at the Battelle Columbus Division beginning in 1966, Dr. Simonen has studied fracture mechanics and structural integrity addressing the safety and reliability of nuclear pressure vessels and piping as well as other industrial and aerospace structures and components. Since the early 1980s he has lead several studies for the U.S. Nuclear Regulatory Commission of the effects of pressurized 
thermal shock on the failure probability of reactor pressure vessels. This work has advanced the technology of probabilistic fracture mechanics and methods for estimating the number and sizes of flaws in vessel welds. During the 1990s Dr. Simonen was a leader on the behalf of NRC and the American Society of Mechanical Engineers in implementing risk-informed methods for inspecting nuclear piping systems. He has published over 200 papers, articles and reports in the open literature.

Dr. Simonen is a member of the American Society of Mechanical Engineers and serves on the following ASME committees and codes and standards bodies:

- ASME Committee on Nuclear Risk Management

- ASME Research Committee on Risk-Based Technology

- ASME Research Task Force on Risk-Based Inspection Guidelines

- ASME Boiler and Pressure Vessel Code, Section XI.

\section{Dr. Charles W. Stewart}

Dr. Stewart joined Pacific Northwest National Laboratory in 1973 after receiving BS and MS degrees in Mechanical Engineering from Washington State University. His early career was in computational modeling of multiphase fluid systems, including the development and application of major thermal-hydraulic analysis computer programs for nuclear reactor cores. In 1990, Dr. Stewart took leave to study bubble dynamics at Washington State University and received his $\mathrm{PhD}$ in 1993. After returning to PNNL, Dr. Stewart managed PNNL's activities supporting installation of the mixer pump to mitigate flammable gas releases from Hanford waste tank SY-101. He also led tasks to measure the in situ gas volume and waste rheology in several tanks and to understand the mechanisms of gas retention and release in all Hanford waste tanks. In 1998 and 1999, Dr. Stewart led PNNL support for resolution of the "high heat" safety issue by removing waste from Tank $\mathrm{C}-106$. He is currently assisting with the final remediation of gas retention in Tank SY-101.

Dr. Stewart organized the independent evaluation of the Hanford Double-Shell Tank Integrity project for CH2M HILL in May 2001.

\section{Mr. Michael T. Terry}

Mr. Terry is currently a staff member in the Nuclear Systems Design Group, a part of the Decision Applications Division, at Los Alamos National Laboratory. He holds a BS in Mathematics from the University of New Mexico and an MS in Mechanical Engineering from Washington University. Mr. Terry is also a licensed Professional Engineer in both New Mexico and Colorado and is a Certified Energy Auditor in New Mexico.

Mr. Terry has extensive experience in nuclear and process safety; engineering, design, and construction of nuclear and non-nuclear facilities and processes; program and project design and implementation; and project management and administration. Technical management experience includes a wide variety of applications ranging from leading small to large design teams to the 
more diverse skills required to "influence" contributors from different organizations, and with differing agendas, to work together toward a common solution meeting user requirements.

From 1998-2002, Mr. Terry was the Safety Technology Integration Manager with the Tanks Focus Area, responsible for managing development of several technologies to more safely assess the structural and hydraulic integrity of high-level waste tanks. Under his leadership, intra-site working groups were formed to address common problems, solutions, and lessons learned. Such groups include the Electrochemical Noise Working Group, the Tank Integrity Inspection Working Group, and the Environmental Management Science Program Corrosion Project discussion group on electrochemical noise. Most recently he has been asked to provide expertise in closure requirements related to DOE Order 435.1, Radioactive Waste Management.

\section{Dr. Philip E. Zapp}

Dr. Zapp is a Fellow Engineer at the Savannah River Technology Center, Westinghouse Savannah River Company. He received a BA in Physics from Cornell University and a PhD in Metallurgical Engineering from the University of Illinois at Urbana-Champaign.

Dr. Zapp has 22 years of research and development experience in government and industry laboratories. His varied background includes experience in materials science, including polymers, radiation damage, tritium effects on materials, advanced non-destructive testing of welds, corrosion of metals, and coatings. He has 15 years of experience in corrosion R\&D of engineering alloys, related to chemical processing and high-level radioactive waste storage and processing. He has done extensive work in localized corrosion of carbon steel and has developed chemistry control limits for dilute radioactive waste storage and processing.

$\mathrm{He}$ is a member of NACE International. Activities related to this membership include participation in corrosion science and technology and corrosion in nuclear systems committees, and chairman of task group on radioactive liquid waste storage, and chairman of nuclear systems symposium, 2001. He is a member of ASTM and a former member and past chairman of Savannah River Chapter (1987-88), ASM International.

Dr. Zapp was a member of the senior review committee tasked with evaluating the Hanford Double-Shell Tank Integrity project in May 2001. 



\section{Appendix C}

\section{Acceptance of Recommendations by $\mathrm{CH} 2 \mathrm{M}$ HILL}


CORRESPONDENCE DISTRIBUTION COVERSHEET

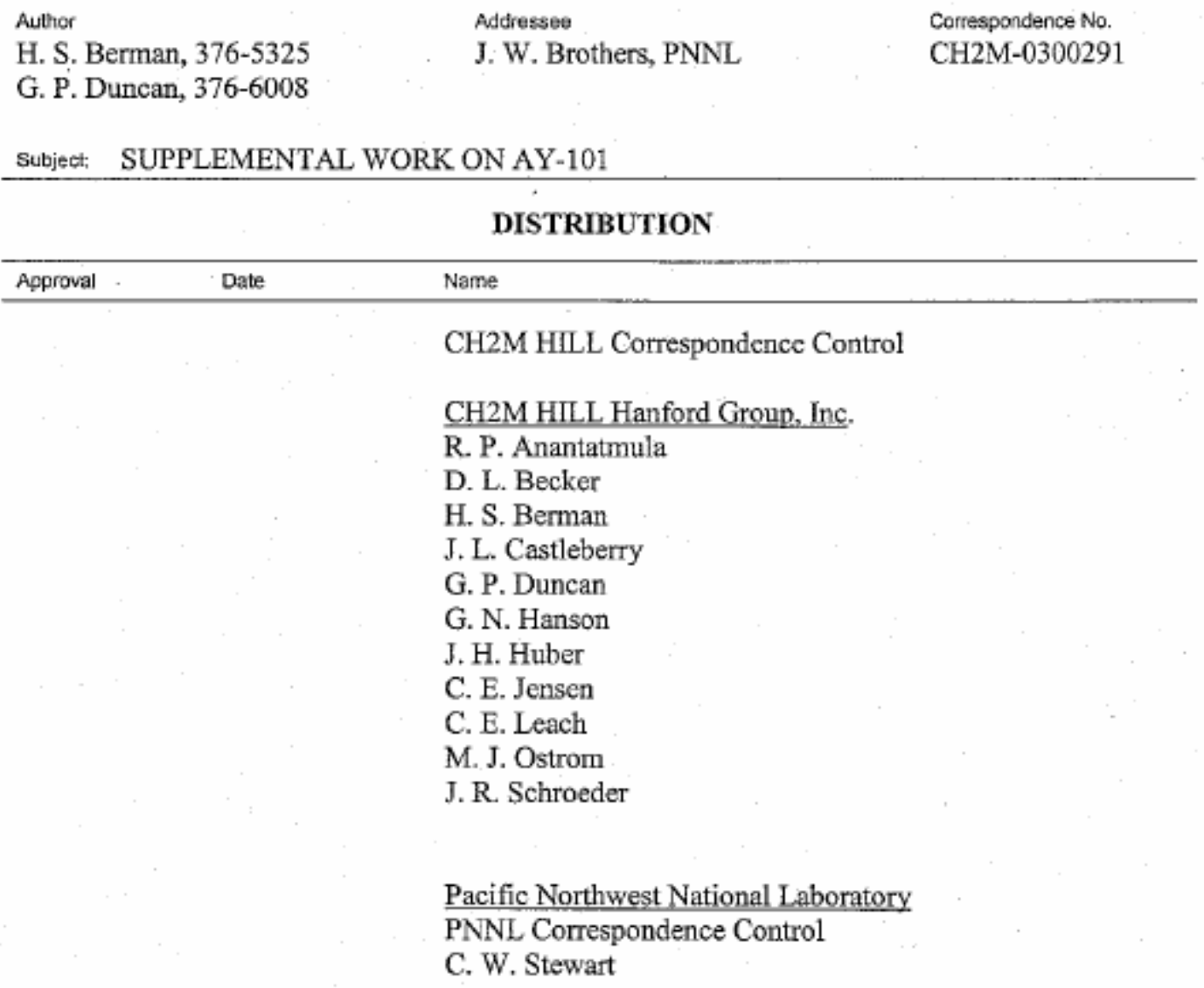




\section{SUPPLEMENTAL WORK ON AY-101}

As you are aware, the AY-101 Fitness for Service Report (RPP-13361) is being finalized, and Pacific Northwest National Laboratory (PNNL) has performed a peer review of the information on the report. As a result of the PNNL review and discussions with CH2M HILL Hanford Group, Inc. (CH2M HILL) personal, several items of supplemental work were considered necessary to accomplish. The items, commitment, status and timing are as follows:

1. Primary Tank Waterline Ultrasonic Testing (UT) - Since the major defect found in AY-101 exists at a region of prior waste levels ( 321 to 351 -inches), it is considered prudent to re-UT the region after it is rewetted when the waste level is raised above the 321 -inch mark. The commitment is to perform a UT scan of portions of the prior waterline defect area, and sample the new waterline region approximately $2-4$ years after rewetting, to detect and monitor any unusual corrosion. This commitment is being programmed into the out-year program plans, since it is projected that the tank will be filled in fiscal year (FY) 2005-2006, a UT will be scheduled for FY 2008.

2. Secondary Liner UT - A UT sample of both the vertical wall and the annulus floor are desirable to obtain information on any degradation from the prior annulus corrosion. However, since the wall thickness is robust, and the stress levels low, these analyses are not required before returning AY-101 to unrestricted service. However, the intent is to accomplish these UTs as soon as practical. The secondary UT work is scheduled to be accomplished this FY.

3. Psychrometric Measurement - The leaking valve that was considered responsible for the water intrusion into AY-101 annulus, had its water supply source capped off. However, a post-repair psychrometric was never run to confirm that all annulus water intrusion sources had been corrected. This psycrometric testing is to be accomplished this fiscal 
year. However, since the operating annulus ventilation can accommodate 150 gallons per day of excess water, this measurement is not considered necessary prior to returning AY-101 to unrestricted use.

4. Leak Detector Testing - Prior to raising the tank level above the present 80-inch limit, test and confirm that the annulus leak detectors are operating properly. Status: Tank Farm Operations routinely checks these items, but has been tasked by Double-Shell Tank Integrity Project to complete an operational check before the level is raised. It is expected that this will be accomplished in this FY.

In addition, the primary tank bottom plate may be accessible through some of the air slots in the concrete bottom pad, using the recently modified Remote Ultrasonic Tank Inspection (RUTI) device. Some thickness measurements of the tank bottom plate are desirable to obtain information on any degradation from the prior annulus corrosion. However, since the bottom plate thickness is robust, and the stress levels low, this analysis is not required before returning AY-101 to unrestricted service. Because of limited access to the primary tank air slots in the AY Farm a best effort attempt with existing technology (RUTI) will be accomplished this fiscal year.

CH2M HILL appreciates the PNNL diligence and scrutiny in providing a peer review of this important issue. Please let me know if there is any other information we can provide.

Very truly yours,

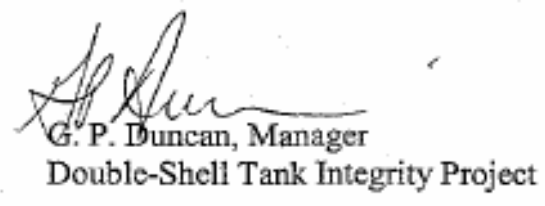

$1 b$ 
